\title{
Nombres en -ame(n) en el español de los siglos XVI y XVII
}

\author{
Nouns ending in -ame $(n)$ in $16^{\text {th }}$ - and $17^{\text {th }}$-century Spanish
}

\section{David Prieto García-Seco ${ }^{1}$}

1 Universidad de Murcia, España

Recibido: 12-12-2019; Aceptado: 15-02-2020

\section{Resumen}

Este trabajo estudia un grupo de sustantivos colectivos terminados en -ame(n) que comenzaron a utilizarse en español en los siglos XVI y XVII; los sustantivos en cuestión son barrilamen, bestiame(n), botamen, cordame(n), cerdamen, leñame(n), maderame(n), pelamen, poleame(n) y velame(n). En primer lugar, se muestra de qué manera evolucionó el sufijo latino -men en distintas lenguas romances con el objeto de conocer en cuáles desarrolló un valor semántico colectivo. Seguidamente, se aborda el estudio monográfico de los diez sustantivos mencionados, prestando especial atención a su origen y a su trayectoria histórica. Por último, se exponen unas consideraciones finales en las que se reflexiona, entre otros aspectos, sobre la terminación - $a m e(n)$ en español y sobre la procedencia de las voces estudiadas.

Palabras clave: historia del léxico español; siglos XVI y XVII; sustantivos colectivos en -ame(n); lenguas romances; préstamo.

\begin{abstract}
This article studies a group of collective nouns ending in -ame(n) that were first used in Spanish in the 16 th and 17th centuries. The nouns under discussion are barrilamen, bestiame(n), botamen, cerdamen, cordame(n), leñame(n), maderame(n), pelamen, poleame(n) and velame(n). The article first shows the evolution of the Latin suffix -men in several Romance languages in order to identify the languages that developed a collective meaning. Next, the ten nouns are studied individually, with special attention to their origin and historical development. To end, the final remarks present a global reflection on the ending $a m e(n)$ in Spanish and on the provenance of the words surveyed.
\end{abstract}

Keywords: history of Spanish lexicon; $16^{\text {th }}$ and $17^{\text {th }}$ centuries; collective nouns in -ame(n); Romance languages; borrowing. 


\section{INTRODUCCIÓN}

El Diccionario de la lengua española (2014) de la Academia registra ocho sustantivos terminados en -amen (o -ame) que presentan un valor semántico colectivo. A este valor se alude en el artículo dedicado al sufijo -amen, donde se indica: "en sustantivos españoles derivados tiene significado colectivo. Velamen, cerdamen, maderamen, pelamen". Igualmente, la Nueva gramática académica asegura que el "sufijo -amen forma una serie breve de nombres colectivos", y repite los cuatro nombres que cita el diccionario usual (RAE/ASALE 2009: § 6.13u). Exceptuando algunas otras obras que, de manera fragmentaria y sin la profundidad que requiere el asunto, se han referido a los sustantivos en -ame(n), puede decirse que básicamente este es el conocimiento que tenemos de tales voces, pues no existe un trabajo que se haya dedicado de manera exclusiva a su análisis.

El objetivo específico de este artículo es, en consecuencia, estudiar monográficamente los sustantivos colectivos barrilamen, bestiame(n), botamen, cerdamen, cordame(n), leñame(n), maderame(n), pelamen, poleame(n) y velame(n), atendiendo de una manera especial a los tres siguientes aspectos: a) las primeras documentaciones, b) la procedencia y c) la difusión posterior. Ello conlleva trazar la trayectoria histórica de tales voces con el propósito de establecer las características comunes que presentan en tanto que forman un grupo limitado de elementos léxicos con una morfología común y un valor colectivo compartido.

Para alcanzar dicho objetivo se ha recurrido a distintas fuentes de información léxica, que podemos dividir en tres grupos: a) obras lexicográficas, b) corpus y c) otras fuentes de información. En primer lugar, nos hemos servido de diversas obras lexicográficas tanto del español como de otras lenguas. Para el catalán hemos acudido, entre otros, al Diccionari Aguiló. Materials lexicogràfics aplegat per Marian Aguiló i Fuster (1915-1934), al Diccionari Balari. Inventario lexicográfico de la lengua catalana (1927-1928), al Diccionari català-valencià-balear (1930-1962) de Alcover y Moll, al Vocabulari de la llengua catalana medieval de Lluís Faraudo de Saint-Germain, y al Diccionari etimològic i complementari de la llengua catalana (1991-1995) de Joan Corominas. Para el italiano se han consultado, principalmente, el Dizionario della lingua italiana (1865-1879) de Tomaseo y Bellini, el Grande dizionario della lingua italiana (1961-2002) de Salvatore Battaglia, el Tesoro della Lingua Italiana delle Origini (1997-2019), dirigido por Paolo Squillacioti, y el Dizionario Etimologico della Lingua Italiana (1999) de Cortelazzo y Zolli. En cuanto al portugués y al gallego, han sido utilizados, entre otros, el Diccionario da lingua portugueza (1831) de António de Morais Silva, el Novo diccionario da lingua portugueza (1850-1853) de Eduardo de Faria, el Dicionário etimológico da língua portuguesa (2003) de José Pedro Machado, el Dicionário etimológico da língua portuguesa (2010) de Antônio Geraldo da Cunha, el Corpus Lexicográfico do Português de la Universidad de Aveiro y el Centro de Lingüística de la Universidad de Lisboa y el Dicionario de dicionarios del Instituto da Lingua Galega. Estas obras lexicográficas, junto con los repertorios de español manejados, se recogen en la bibliografía.

La segunda fuente a la que hemos acudido para delinear la vida de los sustantivos estudiados son los distintos corpus que pueden consultarse en línea, tanto del español (CNDH, CORDE, CREA, etc.) como de otras lenguas (CICA, CIPM, CTILC, etc.). Ha de indicarse que, tras la cita de cada texto, señalamos qué fuente nos lo ha proporcionado. Ello no quiere decir que se haya manejado la edición utilizada en dicha fuente; de hecho, casi siempre hemos acudido a otras ediciones, que o bien eran las primeras, o bien las teníamos a mano para citarlas convenientemente. 
En tercer lugar, se han empleado otras fuentes que ofrecen información relevante para nuestro objeto de estudio. Al respecto, debemos mencionar por su riqueza léxica el Fichero general de la Academia. También es justo encarecer otros recursos de acceso en línea que en los últimos años están prestando un servicio extraordinario a los estudios filológicos, especialmente de corte diacrónico; nos referimos, entre otros, a las bibliotecas y hemerotecas digitales, a la página de Google Books o a la de Internet Archive. Estas últimas fuentes, que permiten la búsqueda y localización de voces en textos que previamente han sido digitalizados y sometidos a un proceso de OCR (optical character recognition), ofrecen una información léxica riquísima de cuya consulta no puede abstraerse quien desee abordar hoy día el estudio del léxico español desde una perspectiva histórica. Al término del trabajo se recogen los corpus que nos han auxiliado en nuestra labor y las restantes fuentes de información, consultados durante los meses de octubre y noviembre de 2019.

Este trabajo se estructura en cuatro apartados, incluida la presente introducción. En $\S 2$ se ofrece una visión de conjunto sobre la procedencia y el desarrollo de los sufijos que en diversas lenguas romances tienen el valor colectivo que nos incumbe. En este mismo apartado se lleva a cabo una aproximación al sufijo - $\operatorname{ame}(n)$ en español y se reflexiona sobre las propuestas interpretativas que ha recibido. El apartado 3, que constituye la parte principal del estudio, está dividido en diez subapartados, tantos como los sustantivos que son objeto de análisis. Cierran el estudio unas consideraciones finales en $\S 4$.

\section{EL SUFIJO -MEN: DEL LATÍN A LAS LENGUAS ROMANCES}

La terminación -MEN, -INIS tenía una función principal en latín: la derivación de sustantivos a partir de verbos (DICTĀMEN, -ǏNIS 'acción de dictar' < DICTŌ 'decir repetidamente', 'dictar'; FLĀMEN, ĬNIS 'soplo, aliento', 'viento, brisa' < FLŌ 'soplar', 'exhalar'; HORTĀMEN, -ǏNIS 'exhortación', 'arenga' < HORTOR 'exhortar', 'estimular, animar'; IRRĪTĀMEN, -ǏNIS 'estímulo, incentivo' < IRRĪTŌ 'excitar, estimular, provocar'; SEDĀMEN, -ǏNIS 'sedante' < SĒDO 'hacer sentarse', 'hacer reposar', 'calmar'1). Además de expresar resultado, instrumento o acción, el sufijo -MEN desarrolló en latín otra función, la de formar sustantivos colectivos, primero a partir de verbos (EXĀMEN, -ǏNIS 'enjambre de abejas', 'muchedumbre' < EXĬGŌ 'echar fuera', 'expulsar' < EX y ĂGŌ) y luego también, de manera novedosa, sobre nombres (PŬLPĀMEN, -ĬNIS 'guiso de pedazos de carne' < PŬLPA, -AE 'carne'; LIGNĀMEN, -ǏNIS 'cosa hecha de leña' < LĪGNUM, -Ī; cfr. § 3.3). Meyer-Lübke se refería así a este cambio:

En effect, dans les dérivés issus de verbes qui sont à leur tour dérivés d'un nom de chose, tel que calceare (chausser) de calceus (le soulier) p. ex., comme l'idée de chose précède celle d'activité, l'idée abstraite est éliminée par l'idée collective: calceamen ne signifie plus l'action de chausser, mais l'ensemble des objets nécessaires à la chaussure, le soulier, par conséquent une masse de calcei. De cette modification résultait en même temps la possibilité d'adapter ce suffixe, non plus uniquement à des thèmes verbaux, mais aussi souvent à des nominaux; et de fait on trouve lateramen (maçonnerie) déjà chez Lucrèce, pulpamen (plat de viande) dans l'abrégé de Tite-Live, linteamen chez Apulée, etc. (Meyer-Lübke 1895: 5312; cfr. Pharies 2002: 395-396).

En Les dérivés latins en -men et -mentum Perrot (1961: 39, 40 y 42) menciona otros nombres latinos en -ĀMEN con valor colectivo: AFFĀMEN, -ǏNIS "parles adressées à quelqu'un"; CRASSĀMEN, -ǏNIS "sédiment, dépôt"; PUTRĀMEN, -ǏNIS "amas de pourriture"; SANGUINĀMEN, -ǏNIS "mets à base de sang". 
Aunque se refiere al "sens collectif" de estas y otras voces, dicho autor prefiere hablar de un valor semántico "de especie": "Les mots cités pour les périodes précédentes montrent qu'un sens collectif ou un sens "d'espèce" s'attache le plus souvent aux dénominatifs" (Perrot 1961: 204-205; cfr. 260 y ss.). El sufijo latino -MEN, según Meyer-Lübke (1895: 531-532), encontró acomodo en varias lenguas romances, en las que dio lugar a la formación de diversos sustantivos colectivos 3 . En relación con el italiano, indica:

En italien, -ame forme uniquement des collectifs et est très employé: bestiame (bétail), cor[ame] (objets en cuir), ferr[ame] (objets en fer), fun [ame] (funin), midoll[ame] (moelle), oss[ame] (ossements), pell[ame] (peaux), pelicci[ame] (pelleterie), vasell[ame] (vaisselle), etc. (Meyer-Lübke 1895: 532).

A esta lista pueden añadirse los siguientes nombres: bottame 'barriles', carname 'masa de carne putrefacta', fogliame 'follaje', fruttame 'frutas diversas', ottoname 'objetos de latón', pollame 'aves de corral', scatolame 'conjunto de cajas' o tavolame 'maderas'. Además de los derivados nominales, Meyer-Lübke menciona para el italiano algunos posverbales: "On trouve aussi des dérivés à thème verbal: casc[ame] (chute), gett[ame] (choses rejetées), mescol[ame] (mélange), etc., auxquels nous devons encore ajouter un terme dialectal, l'a[ncien] gén[ois] inzisame (salade), qui a son correspondant exact dans le catal. ensiam" (ibíd.; cfr. ensiam en DCVB: "Conjunt de bocins de verdura, hortalissa, olives, etc., amanits amb oli, sal, vinagre, per a menjar-se abans dels plats principals o durant la menjada d'aquests").

Al igual que el italiano, el portugués también posee un número considerable de voces en -ame (y algunas en -ama) con valor colectivo:

Le portugais y joint encore balame (tas de balles), besti[ame] (bétail), corre[ame] (objets en cuir), folh[ame] (feuillage), grav[ame] (charge), maçame (maçonnage) et les termes de marine cavern[ame], fil[ame], tonel[ame], verg[ame], enfin ossama (squelette) et courama (objets en cuir), tous deux influencés dans leur genre par les mots en -menta. (Meyer-Lübke 1895: 532).

Añadiremos nosotros algunos otros sustantivos portugueses en -ame (importa subrayar que, al igual que algunos de los mencionados, los cuatro últimos pertenecen a la náutica): cartuchame "Porção de cartuchos para armas de fogo" (Vieira 1871-1874: s. v.), cordame "Conjunto de cordas; reunião de cabos do aparelho dum navio" (Barbosa 1992: s. v.), massame " "o complexo de todos os cabos que se empregam no aparêlho de um navio" (Amorim 1841: s. v.), vasilhame "o agregado de toneis, pipas, etc., em que nos navios se conduz a aguada" (Amorim 1841: s. v) y velame "nome generico que comprehende todas as vélas, que entram no complexo de qualquer embarcação" (Amorim 1841: s. v.).

Aunque el romanista suizo no se refirió al catalán en relación con el sufijo -ĀMEN latino, es necesario que se traiga a colación aquí, puesto que es otra de las lenguas neolatinas que presentan un número elevado de nombres colectivos con el sufijo que estamos tratando. Entre otros sufijos colectivos, Fabra (1912: 235) menciona -am y pone diversos ejemplos: bestiam, brancam, cordam, corretjam, costellam, cuiram, donam, fullam, fustam, paperam y vigam. Forteza y Cortés (1915: 110), a propósito de las terminaciones - am, -im y -um, indica que en esta lengua existen "Derivaciones catalanas numerosas, que generalmente son colectivas o intensivas: bayam, cordam, enciam (Val. 
encisam) de INCISUS, llenyam - ventim, verrim, ruxim, - carnum, grexum, cabrum". Por su parte, Moll (2006[1952]: 242) insiste:

En el seu ús ple com a sufix catala, -am té sentit col-lectiu molt accentuat, indica multitud o gran volum: arrelam, aviram, banyam, bigam, brancam, budellam, costellam, fullam, fustam, paperam, rocam. De vegades es reforça i pren la forma -atam: rocatam, volatam 'multitud d'aus de corral's.

A los sustantivos catalanes en -am mencionados pueden añadirse los siguientes, con los que se pretende poner de manifiesto aún más la productividad de dicho sufijo en esta lengua: balconam "Multitud de balcons" (DCVB), brotam "Multitud de brots" (DCVB), corfam "Conjunt de corfes" (DCVB), crossam "Quantitat, còpia de crosses" (Faraudo), dardam "Quantitat, provisió de dards" (Faraudo), dogam "Multitud de dogues de bóta" (DCVB), einam "Conjunt de recipients destinats a tenir líquids, i principalment els que s'empren a la cuina i a la taula de menjar" y "Conjunt d'eines o utensilis d'un ofici o professió" (DCVB), fardam "Conjunt de coses inútils o que fan nosa" (DCVB), gerram "Conjunt de gerres" (DCVB), macam "Multitud de macs" (DCVB), maçam "Conjunt de maços" (DCVB), pedregam "Multitud de pedres; lloc ple de pedres" (DCVB), sogam "Conjunt o gran quantitat de sogues; cordam" (Faraudo), testam "Multitud de tests, de terrissa rompuda" (DCVB), trossam "Conjunt de trossos, principalment de pedreny trossejat quan s'enderroca un edifici" (DCVB), viratam "Provisió, multitud de vires" (Faraudo) y viretam “Conjunt de vires o sagetes" (DCVB) ${ }^{6}$.

En el caso del español debemos referirnos a dos manifestaciones léxicas. Por un lado, tenemos - como sucede en el resto de las lenguas tratadas - los latinismos que penetraron en el idioma en distintos periodos, principalmente con el sentido de acción: certamen, dictamen, examen, foramen, gravamen, libamen, vejamen, etc. (Véanse otros en Pharies 2002: 395). Por otro lado, el sufijo -MEN latino dio lugar en español a un resultado fonético bien conocido, el sufijo -(a)mbre, fruto de la evolución regular de la terminación de acusativo en latín vulgar -ĀMǏNEM7 . Hanssen (1913: 137138), en relación con la desinencia latina -MEN, indica: "En romance, los sustantivos de esta categoría son a menudo colectivos: raigambre". García de Diego (1914: 191), que prefiere partir del sufijo -mbre, afirma que este "tiene sentido colectivo en techumbre, raigambre, corambre, urdimbre, pelambre, herrumbre"8. Por tanto, tenemos en español un pequeño grupo de sustantivos terminados en -ambre que poseen una noción colectivo-abundancial (cfr. Alemany 1920: 16-17; RAE/ASALE 2009: $§ 6.13 v$ ); se explica así que Rainer (1993: 402) solo hable de cuatro colectivos: "Das Suffix -ambre erscheint in vier Kollektiva: cochambre (vgl. cochino), corambre, pelambre, raigambre". Pharies (2002: 395), por su parte, viene a afirmar lo mismo, que la "forma popular española de -āmen, -ambre, muestra en comparación con estas lenguas [italiano, portugués y catalán] poco vigor en este sentido [el valor colectivo]"9.

Pues bien, al reducido grupo de latinismos en -amen y de sustantivos en -ambre hay que sumar otro grupo de voces terminadas en -ame(n) con valor colectivo que comienzan a utilizarse en español durante los siglos XVI y XVII. Importa subrayar, en primer lugar, que se trata de un conjunto de nombres muy pequeño, pero no por ello, desde luego, exento de interés; los sustantivos en cuestión son barrilamen, bestiame(n), botamen, cerdamen, cordame(n), leñame(n), maderame(n), pelame(n), poleame(n) y velame(n) ${ }^{10}$. Rainer (1993: 403), en tales casos, habla de la función colectiva del sufijo -amen, que daría lugar a formaciones lingüísticas estándar: "Das Suffix -amen hat kollektive Funktion. Standardsprachliche Bildungen wären botamen, maderamen, pelamen, velamen”. La cuestión es la siguiente: ¿de dónde proceden estos sustantivos? A propósito de la 
terminación -ame, Alemany (1920: 17) se refirió a bestime, leñame y poleame como nombres "de formación castellana". Poco después, en el artículo dedicado a -amen, tras mostrar algunos latinismos (certamen, dictamen, etc.), el mismo estudioso indicaba que "a semejanza de los [nombres] anteriores, ha formado el castellano algunos, todos derivados nominales y con significación colectiva que no tenía el sufijo latino, como botamen, de bota y bote; cerdamen, de cerda; pelamen y pelambre, de pelo; velamen, de vela". ¿Se puede hablar, realmente, de formaciones castellanas?

El diccionario usual de la Academia (2014) recoge los dos siguientes valores del sufijo -amen: 1) "Aparece en sustantivos tomados del latín. Dictamen, gravamen, examen, certamen" y 2) "En sustantivos españoles derivados tiene significado colectivo. Velamen, cerdamen, maderamen, pelamen". Aunque de menor interés para nuestro propósito, conviene plantearse la oportunidad de que un diccionario de español recoja una información morfológica que no atañe a esta lengua, sino a la latina. Lo cierto es que no parece relevante, ni oportuno, que un diccionario de español ofrezca información sobre la morfología latina; en realidad, es suficiente con que la procedencia de dichos latinismos se exhiba en los paréntesis etimológicos de cada uno de ellos ${ }^{11}$. Nadie esperaría que un diccionario español incluyera un artículo dedicado al sufijo latino -bulum y en él se indicara que en la lengua de Cicerón se formaron voces que, con ciertas evoluciones fonéticas, llegaron a nuestro idioma, como sucede con acetábulo, conciliábulo, patíbulo o turíbulo.

Sin embargo, más importante que lo anterior es determinar si es adecuado el enunciado en el que se afirma que el sufijo -amen "En sustantivos españoles derivados tiene significado colectivo"12. No nos referimos, claro está, al valor colectivo de los nombres en cuestión, que está fuera de toda duda, sino a la conveniencia de señalar que tal valor ocurre en "sustantivos españoles derivados"; en otras palabras, lo que se está afirmando — al igual que hizo Alemany- es que el sufijo -amen, mediante derivación, ha dado lugar en español a determinados sustantivos. Esta concepción es la que se mantiene en la Nueva gramática de la lengua española (2009), donde se incluyen los nombres colectivos en -amen dentro de la derivación nominal y, además, se menciona el patrón "N-amen: vela > velamen" entre los sufijos "más productivos" (RAE/ASALE 2009: $§ 5.1 \mathrm{~b}$ ). Más adelante, esta misma obra insiste en la capacidad del sufijo de crear sustantivos colectivos, si bien niega su productividad: "El sufijo -amen forma una serie breve de nombres colectivos: cerdamen, maderamen, pelamen, velamen” (ibíd.: $§ 6.13 \mathrm{u})^{13}$.

Como queda dicho en $\S 1$, en este trabajo nos ocuparemos monográficamente de los diez sustantivos en -ame(n) mencionados, con el objeto de conocer su cronología, su procedencia, las características que comparten y las que los diferencian, de manera que estemos en condiciones de dar una respuesta a los extremos planteados.

\section{NOMBRES EN -AME(N) EN EL ESPAÑOL DE LOS SIGLOS XVI Y XVII}

El diccionario vulgar de la Academia (2014) recoge ocho de los diez sustantivos estudiados en este trabajo, con los lemas barrilamen, botamen, cerdamen, leñame, maderamen, pelamen, poleame y velamen ${ }^{14}$. En este trabajo no los ordenamos según el abecé, sino que su disposición responde a razones expositivas. Agrupamos, en primer lugar, los nombres que presentan variantes fonéticas: $\operatorname{velame}(n), \operatorname{bestiame}(n)$, poleame(n), leñame(n), maderame(n) y cordame(n). Dentro de este grupo, hemos estimado oportuno ocuparnos, en este orden, de los nombres leñame(n) y maderame(n), 
puesto que el estudio del primero ayuda a comprender la aparición del segundo. Por otro lado, las voces botamen y barrilamen presentan, a diferencia de las anteriores, la peculiaridad de documentarse únicamente con tales formas, lo que justifica, junto con los motivos que se expondrán más adelante, que sean tratadas en el lugar que ocupan. Cerdamen y pelamen se estudian al final de este apartado, no solo porque son las últimas voces que se unieron a esta serie, sino sobre todo por su carácter especial, que las distingue nítidamente de los demás nombres colectivos.

\section{1. $\operatorname{Velame}(\mathbf{n})$}

En primer lugar, debemos hacer algunas consideraciones sobre las voces velambre y velamen 'velo, cubrimiento'. Las dos primeras están emparentadas etimológicamente, pues velambre es el resultado de la evolución regular del acusativo latino VELĀMǏNEM (VELĀMEN, -ǏNIS < VELĀRE 'velar, cubrir con un velo', 'rodear, envolver', 'ocultar, disimular'). Aunque parece que velambre no tuvo mucha circulación en español, se documenta con el sentido de 'velación, ceremonia de casamiento' en una obra de Alfonso X:

(1) [1259] En esta tercera costellation judga que quiça tomara muger sin uelambres et sera como barragana. (Alfonso X, Libro de las cruces, eds. Lloyd A. Kasten y Lawrence B. Kiddle, Madrid-Madison, 1961, p. 144b; Fich. Ac.) ${ }^{15}$.

Por otro lado, tenemos el latinismo velamen, que presenta la misma etimología que velambre. Esta voz tuvo algún uso en español desde el siglo XIV hasta principios del XVII (cfr. velame ${ }^{1}$ en $G D L I$ ):

(2) [1427-1428] [...] segúnd aquí quiso aquel velamen de la istoria de las arpías. (Enrique de Villena, Traducción y glosas de la Eneida, en Obras completas, II, ed. Pedro M. Cátedra, Madrid, Turner, 1994, p. 714; CORDE).

(3) [1535] Alegoría con quél quiso dar a entender debaxo de velamen lo que, hablando a la llana, no oviera de qué se pudiera algún cuerdo o prudente maravillar. (Gonzalo Fernández de Oviedo, Historia natural y general de las Indias, ed. José Amador de los Ríos, Madrid, 1855, t. IV, p. 482b; Fich. Ac.).

(4) [1554] Dízense también secretos y escondidos los lazos dela auaricia porque tienen algún velamen y cobertura con que escusarse al principio. (Francisco de Osuna, Quinta parte del Abecedario espiritual, Burgos, 1554, fol. 199v.ㅜ; CORDE).

(5) [c1573-1581] Amparándose con el velamen de la noche. [...] Con la escuridad y belamen de las noches. (Fr. Pedro de Aguado, Historia de Santa Marta y Nuevo Reino de Granada, ed. Jerónimo Bécker, Madrid, RAH, 1916, t. I, p. 823 y 1917, t. II, p. 56; Fich. Ac.).

(6) [1600-1605] Le abrió Dios los ojos, quitándole el velamen de la ceguedad [...]. Quitarles [Dios] el velamen, no de los ojos, sino de los coraçones ciegos [...]. 
Quitole el velamen que tenía sobre el coraçón [...]. Dixo Dios allí sus pensamientos, no solo debaxo el velamen de metáforas y alegorías [...]. Tienen el velamen de Moysen delante de los ojos. (Fr. José Sigüenza, Historia de la Orden de San Jerónimo, ed. Juan Catalina García, Madrid, Bailly Bailliere, 1907, t. i, p. 442a y 1909, t. ii, pp. 37b, 179a, 191b y 497b; CORDE).

Pues bien, en tercer lugar, y sin parentesco etimológico con las dos voces anteriores, se encuentra el nombre velamen 'conjunto de velas de una embarcación' (cfr. Pharies 2002: 397, n. 5). Aunque en español documentamos este sustantivo en la segunda mitad del siglo XVI, su verdadera difusión se produjo en la centuria siguiente.

(7) [1565] Los angeos que se enviaron al Puerto de la navidad fueron pocos y esos se gastaron en las velas, de suerte que se truxo muy rruin belamen de rrespeto e que las dichas naos vinieron sin ninguna xarcia de rrespeto. (Colección de documentos inéditos relativos al descubrimiento, conquista y organización de las antiguas posesiones españolas de ultramar, Madrid, Real Academia de la Historia, 1887, t. 3, II, p. 308; Archive).

(8) [1595-1603] El viento os llama y fauorable sopla / por la popa el lienço del velame herido. (Lope de Vega Carpio, La santa liga, en Décima quinta parte de las comedias de -, Madrid, 1621, fol. 116r.․ㅜ CORDE).

(9) [1598] Aunq[ue] de roble y de laurel no enrames, / España, este sagrado Mausoleo, / sino de lienços que combata Eolo, / velas, bastardos, gauias y velames [...]. (Lope de Vega, La Arcadia, Madrid, 1603, fol. 97v.o; CORDE).

(10) [1604] Velame, Appareil de nauire. (Jean Palet, Diccionario muy copioso de la lengua española y francesa, París, 1604; NTLLE).

(11) [1617] Velame [...] navis velamina. sailes, trimming up of a ship. (John Minsheu, Vocabularium Hispanicum Latinum et Anglicum copiossimum, London, 1617; NTLLE).

(12) [1619] Vaya Zulema por el mar, y al viento / desembuelua las Lonas del Velame; / lleue cien naues, si bastaren ciento. (Lope de Vega Carpio, Lo que hay que fiar del mundo, en Parte de las comedias de -, Madrid, 1619, fol. 195r.o; GB).

(13) [1628] A este navío avían solamente tomado el Piloto, siete negros i el velamen. (Tomás Tamayo Vargas, Restauración de la ciudad del Salvador i Baía de TodosSanctos, en la Provincia de Brasil, Madrid, 1628, fol. 33v.․; GB).

(14) [1639] Para la sombra del tablado principal y los demás se pusieron 22 árboles [...] y en ellos se hizieron firmes las belas [...] con muchas betas de cáñamo con sus motones, poleas y quadernales, con que quedó el belamen tan llano y firme [...]. (Fernando de Montesinos, Auto de la fe celebrado en Lima a 23 de enero de 1639, Lima, 1639, fol. ๆB[1r.ํ]; Archive). 
Antes de que la lexicografía española, con el Diccionario de autoridades a la cabeza, registrara el lema velamen ${ }^{16}$, lo habitual es que la lexicografía bilingüe preacadémica recogiera la variante velame (cfr. 10-11 y NTLLE), que es la que se documenta en la mayoría de los primeros textos que contienen este sustantivo. Sin embargo, la forma velame pronto dejaría paso a velamen, que es la variante que presentan casi todos los textos a partir de los años veinte del siglo XVII. Esta última variante muestra un incremento fonológico nasal debido seguramente a la atracción analógica del latinismo homónimo velamen. Importa indicar que, a diferencia de lo que les sucedió a otras voces en -ame(n) con valor colectivo, el sustantivo velamen arraigó en español desde entonces y ha llegado a nuestros días con plena vitalidad ${ }^{17}$.

Aunque el italiano conoce la voz velame ("Marin. Disus. Velatura di un'imbarcazione"; GDLI: s. v. velame $^{2}$ ), no parece que haya tenido mucha fortuna en esta lengua (no la registran VAC5 ni Tomaseo y Bellini 1865-1879; GDLI no aporta documentación; cfr. DELI, s. v. vela: "velame, s. $m$. 'complesso delle vele di un bastimento' (1880, E. Laugieri, al quale rinvia il Diz. mar.)”), debido posiblemente a la competencia de la notable polisemia del homónimo velame (cfr. GDLI: s. v. velame $^{1}$ ). Conviene, por tanto, descartar el italiano como lengua transmisora. DCECH (s. v. velo) propone como etimología el catalán velam, documentado desde el siglo XV ${ }^{18}$. DECat brinda el siguiente texto del "Inventario Atarazanas" (1467): "velam de la galera Sancta Eulàlia" (tomado del Diccionari Aguiló, t. VIII, 1934). Faraudo, por su parte, ofrece otro texto del mismo periodo: "En la botiga hont esta lo velam dins la Dressana" (Inventari Drassana de Barcelona, 1489). Habida cuenta de la documentación de que disponemos del catalán velam, parece razonable la etimología que propone Corominas para el español velame $(n)$. Ahora bien, no debe descartarse otra posible vía de acceso al español. El portugués también poseía la voz que nos ocupa al menos desde mediados del siglo XVI. Machado (2003: s. v. velame) duda entre la creación interna o el préstamo del catalán: “De vela + -ame ou do cat. velam?"19. Aunque terminó estandarizándose en portugués la forma gráfica velame, en dicho siglo alternaban velame y vellame, que pueden encontrarse en varios escritos de renombrados historiadores y exploradores de la época:

(15) [1553] Madeira, ferro, breu, velame \& officiaes pera o lauramento das naos. [...] Muytas armas, artelharia, vellame \& enxarcea de oyto vellas, entre naos \& galeões $\&$ eutros nauios de remos que aly estauam. (João de Barros, Segunda decada da Asia, Lisboa, 1553, fols. 24r.ํㅡ y 63v.ㅜ; Archive).

(16) [1563] Aparelhos \& velame dos nauios. (João de Barros, Terceira decada da Asia, Lisboa, 1563, fol. 34r.ㅜ; Archive).

(17) [c1569-1578] Por sua curiosidade \& por ver cousa noua q[ue] nunca aly vira, se veyo logo a nosso bordo \& espantado do aparato \& do vellame da nao. (Fernão Mendes Pinto, Peregrinaçam de - em que da conta de muytas e muyto estranhas cousas que vio \& ouvio no reyno da China, no da Tartaria, no de Sornau, que vulgarmente se chama de Sião, no de Calaminhan, no do Pegù, no de Martauão, \& em outros muytos reynos \& senhorios das partes Orientais, de que nestas nossas do Occidente ha muyto pouca ou nenhua noticia..., Lisboa, 1614, fol. 258v.; GB).

(18) [a1616] Por ser o vento muito rijo, e ter grande velame e ombros se foi acolhendo e çafando dos nossos navios. (Diogo de Couto, Cinco livros da decada doze da historia da India, París, 1645, p. 206a; GB). 


\section{2. $\operatorname{Bestiame(n)}$}

Las primeras documentaciones de bestiame(n) 'conjunto de bestias de carga' pertenecen a la primera mitad del siglo XVI. A lo largo de esta centuria - aunque también encontramos la variante bestiamen o la muy rara voz bestiamento (21) - la forma que se empleó casi exclusivamente fue bestiame.

(19) [1533-1534] Otro mucho daño en el bestiame e casas. [...] Se traían mucho bestiame a la tierra [...]. Lo medio deste bestiame mandó el Maese de campo que se volviese a sus dueños [...]. Sin más esperar que saliesen más turcos y turcas y bestiame, arremetieron con los caballos [...]. Se tomaron veinte y ocho turcos y turcas y mucho bestiame. Como los turcos que estaban en Navarino viesen cómo los cristianos les tomasen sus turcos y turcas y bestiame, les tiran con su artillería. [...] Y también se juntó el bestiame, que fueron hasta trecientas cabezas de bueyes y vacas y búfalos, y quinientos carneros y ovejas y cabras. Este bestiame se dio a saco, y la mayor parte se quedó entre los capitanes. (Martín García Cereceda, Tratado de las campañas y otros acontecimientos de los ejércitos del Emperador Carlos Ven Italia, Francia, Austria, Berbería y Grecia desde 1521 hasta 1545, Madrid, 1873 , t. I, pp. 305, 392, 393, 412, 413 y 414; GB).

(20) [1543] Tanta multitud de bestiame lançado por tan gran anchura de río. (Florián de Ocampo, Los çinco libros primeros dela Crónica general de España que recopila el maestro -, Medina del Campo, 1543, fol. 198r.o-; GB).

(21) [c1550] Y otro día como los del lugar sacasen sus ganados y bestiame el campo y saliesen muchas turcas y turcos, con ellas arremetieron a ellos y los prendieron a todos y les tomaron el bestiame y ganados. [...] Y así se volvieron a Zara con mucha presa de bestiame y de ganado. [...] Pasando el río Po, corrieron las campañas de Turín, donde tomaron mucho bestiame y bestias cargadas de trigo y de harina. [...] Salieron con 250 de a caballo y algunos soldados italianos con ellos a la ciudad de Argos y prendieron todo cuanto bestiamento hallaron y se volvieron con ello a Nápoles. [...] El Maestre de campo San Miguel había ido a la villa de Vino y tomado todo el bestiamen que en ella había. (Alonso de Santa Cruz, Crónica del Emperador Carlos V, ed. A. Blázquez y Delgado-Aguilera y R. Beltrán y Rózpide, Madrid, t. III, 1922, pp. 199, 454, 455 y 532, t. IV, 1923, p. 372; CORDE).

(22) [1553] ¿Y por qué truxistes a congregación de A[donay] al desierto este para morir allí nos y nuestro bestiame? [...] Y abrevarás a la compaña y a su bestiame. [...] Y salieron aguas muchas, y beuió la compaña y su bestiame. (Biblia [de Ferrara] en lengua española, Ferrara, 1553, fols. 71v.․-72r.․; GB).

(23) [1592] Cada Prouincia destas tiene abundancia o esterilidad, así de mantenimientos como de pertrechos y bestiame. (Martín de Eguiluz, Milicia, discurso y regla militar del alférez —, Madrid, 1592, fol. 135v.o; GB). 
(24) [1592] Si bien ay hermosos prados para el pasto del Bestiame. [...] Assí mismo, ay hermosíssimos pastos para el bestiame. (Bernardino de Mendoza, Comentarios de don — de lo sucedido en las Guerras de los Paýses baxos desde el Año de 1567 hasta el de 1577, Madrid, 1592, fols. 4v. $\stackrel{\mathrm{o}}{\mathrm{y}}$ 6v.ㅜㅜ ; GB).

Alemany (1920: 17) considera que bestiame es una voz "de formación castellana" derivada de bestia. Corominas, en cambio, afirma que es un "italianismo sólo empleado por autores del Siglo de Oro, con referencia a Italia o a asuntos militares" (DCECH: s. v. bestia); del mismo parecer es González Ollé (1975-1976: 200), quien indica que estamos ante un préstamo del italiano. En efecto, se trata de un italinismo que en dicha lengua, según TLIO, data de finales del siglo XIII (cfr. GDLI, s. v. bestiame "Deriv. da bestia, col suffisso che indica aggregamento, quantità generica", y DELI, s. v. bestia "s. m. 'insieme delle bestie domestiche (sec. XIV, A. Simintendi)") ${ }^{20}$ y su aparición en los textos se vincula, sobre todo, con distintas campañas militares. Es probable que en la segunda mitad del XVI el nombre todavía se sintiera como ajeno, como una voz extranjera que aún no estaba aclimatada al español. Eso es lo que sugiere el Vocabulario de las dos lenguas toscana y castellana (1570) de Cristóbal de las Casas, donde para el sustantivo italiano bestiame se ofrece el equivalente español "Ganado"21. Durante el primer tercio del siglo XVII se documentan tanto bestiame como, sobre todo, la forma bestiamen, con adaptación a la morfología de otras voces terminadas en -amen, tanto latinismos como nombres colectivos. Nótese que en algún texto (26) conviven las dos formas:

(25) [1613] No se sufre campear con exérçito formado [...] por la falta de yerua y forrages para los caballos, y granos y bestiamen. (Diego Ufano, Tratado de la artillería, Bruselas, 1613, p. 84; Fich. Ac.; cfr. textos 48 y 68).

(26) [1626] Mandaron que la gente inútil y el bestiame de la Isla de Rodas se retirasse con breuedad. [...] Y pusiessen debaxo de las murallas el bestiamen. [...] Leuando a sus galeras y vaxeles grande número de ouejas y bestiamen. [...] Pudiessen comprar y boluer a su ser el bestiamen. (Juan Agustín de Funes, Corónica de la ilustríssima milicia y sagrada religión de San Juan Bautista de Jerusalem, Valencia, 1626, pp. 355b y 388b, 406b, 414a; GB).

(27) [1626] Començó a dar espantosos bramidos o, por hablar en su lenguaje, desabridos rebuznos. [...] quando, por secretos misterios que sabréis adelante, la respondió a vna voz todo el bestiamen del lugar. (Gonzalo de Céspedes y Meneses, Soldado Píndaro, Lisboa, 1640, fol. 219r.o; Fich. Ac.).

(28) [1630] Supo que el socorro del Emperador, atravesados ya los Alpes de los Grisones, con abundancia de vituallas, de bestiame y de todo lo necesario, llegaría dentro de dos días a Bregia. [...] Ocupó aquella Ciudad y, en entrándola, echó fuera el Presidio Veneciano, y en los carros, y con el bestiame que en diversas partes avía proveýdo, bolvió cargado de prisioneros y de algunas piezas de Artillería. (Bartolomé Leonardo de Argensola, Primera parte de los Anales de Aragón, que prosigue los del secretario Gerónimo Çurita, Zaragoza, 1630, pp. 169b y 234b; GB). 
(29) [1634] Amaneció, cubriendo todos los contornos y su bestiamen y ganado sobre la yerua de la plaça. (Gonzalo de Céspedes y Meneses, Historia de don Felipe III, rey de las Españas, Barcelona, 1634, fol. 193r..-; GB).

Su empleo, por tanto, se reduce a los dos siglos indicados, si bien posteriormente podemos encontrar, de manera aislada, algunos textos que contienen la voz bestiame $(n)^{22}$. Es muy probable que a partir del siglo XVIII el uso extemporáneo de dicho sustantivo se deba a su presencia en la lexicografía española, basada fundamentalmente en el registro del lema bestiame en Autoridades (1770), avalado con los textos citados de Bernardino de Mendoza (24, 1.er texto) y Bartolomé Leonardo de Argensola (28, 1. ${ }^{\text {er }}$ texto).

\subsection{Leñame(n)}

La voz llenyam se documenta en el DECat nada menos que con un texto del siglo XIII de la Crònica o Llibre dels feits de Jaime I: "porferim-vos per los hòmens que són aquí de Mansella que us farem un trabuquet a nostra messió, de les antenes e del llenyam de les naus, a honor de Déu e de vós". Para la misma voz DCVB recoge un texto de 1553: "Par llenyam per fer lo rastell del carrer de la Mar" (s. v. rastell, acep. 11). Podemos añadir nosotros este otro texto, de hacia 1328, de la Chrònica o descripció dels fets e hazanyes del inclyt rey don Jaume Primer de Ramón Muntaner: "axi que tota hora Barbaria bastaua aquell lloch de ferre, e dacer, e de tot llenyam, e de totes vitualles, de que venia gran dan a tota Chrestiandat" (Valencia, 1558, fol. 243r.o; GB). DCECH (s. v. leña) recoge la forma leñame, que es como aparece en DRAE desde 1803, e indica que es término "tomado del cat. llenyam o del it. legname". En efecto, en este caso no tenemos elementos de juicio determinantes que nos permitan afirmar taxativamente que fue una u otra lengua la que prestó la voz al español; en algún texto se alude a Cataluña (31) y en otros se habla de campañas bélicas llevadas a cabo en Italia (38).

En italiano legname (antiguamente legniame o ligname) es un sustantivo ricamente documentado desde la primera mitad del siglo XIII (cfr. DELI, GDLI, VAC), de manera que esta pudo ser la lengua transmisora; no es fácil precisar la vía de acceso, aunque quizá ambos idiomas coadyuvaron a la penetración de leñame $(n)$ en español. En cierto momento la Academia llegó a proponer una procedencia directamente latina (DRAE 1970: "Del lat. lignāmen"), pero más adelante rectificó y se decantó por la procedencia italiana (DRAE 2014: "Del it. legname, y este del lat. lignāmen"). En cambio, el Gran diccionario de la lengua española (2012) de Larousse se decanta por la etimología catalana ("leñame (Del cat. llenyam.)").

La voz leñame ( $n$ ) 'conjunto de madera, empleada para diversas construcciones' se vincula como sucede con velamen - con el léxico náutico, aunque no únicamente con él. En los textos que conocemos se emplea de manera habitual para referirse a la madera con la que se construyen las embarcaciones (cfr. 31, 32, 34, 38 y 40), aunque también se alude con dicha voz al material con el que están hechas, por ejemplo, las casas, e incluso un coche de caballos (cfr. 30, 36, 39 y 40). Según la documentación que hemos podido allegar ${ }^{23}$, se trata de un sustantivo cuya vida, nuevamente, se limita a los siglos XVI y XVII; luego, puede afirmarse que su empleo desaparece en español, seguramente a consecuencia de la aparición de maderamen, voz a la que atenderemos en el siguiente apartado. 
[1533-1534] Era una crueldad ver el gran fuego que no tenía remedio por el aire que andaba y por ser todas las casas cubiertas de leñame, que no solamente en esta cibdad, mas en toda la comarca son cubiertas de leñames. (Martín García Cereceda, Tratado de las campañas y otros acontecimientos de los ejércitos del Emperador Carlos $V$ en Italia, Francia, Austria, Berbería y Grecia desde 1521 hasta 1545, Madrid, 1873, t. I, p. 301; GB; cfr. § 3.2, texto 19).

[a1571] Se dio orden [...] hiziesse edificar esta galera de la mejor madera que se hallase en estas partes, por ser el pino de Catalunia el mejor leñame que en Assia, África y Europa se halla. (Juan de Malara, Obras del maestro - . Descripción de la galera real del Sermo. Sr. D. Juan de Austria, Sevilla, 1876, t. I, p. 15; Fich. Ac.).

[1582] A las 40 barcas, de las 80 barcas chatas que han de ir en la dicha armada para los efectos que sabéis, que se han de hacer aquí [...], y a las otras 40 que se han de fabricar en Sevilla la haréis dar para que también se hagan para entonces [...], que el leñame que se ha de llevar de aquí para las 40 que se han de hacer en la dicha Sevilla se va cortando y llevará luego. (La conquista de las Azores en 1583, ed. Cesáreo Fernández Duro, Madrid, 1886, pp. 238-239; Fich. Ac.).

[1583] Tablones y gran cantidad de leñame para lo que se ofreciere ser necessario. (Bernardino de Escalante, Diálogos del arte militar, Sevilla, 1583, fol. 128v.o; Fich. Ac.).

[1590] Carpinteros que aderecen los carros, caxas, hastas, tablas, vigas, varcas, puentes y las demás cosas de leñame necessarias. (Diego de Álava y Viamont, El perfeto capitán, instruido en la diciplina Militar y nueua ciencia de la Artillería, Madrid, 1590, fol. 75r.; GB). 
[1623] Auían estas [galeotas] salido de Sargel el día antes cargadas de bastimentos y leñame para el palacio mismo del Sultán. (Gonzalo de Céspedes y Meneses, Poema trágico del español Gerardo, Madrid, 1623, fol. 231r.o; Fich. Ac.).

[1626] Que rompiéndose algún vaxel de Rodas en los Estados de Túñez, por naufragio o qualquiera otra desgracia, los naturales estuuiessen obligados a fauorecerles, sin tomar cosa alguna, haziendo de sus mercancías y leñamen lo que quisiessen. [...] Cobrando después con ayuda de otras Galeras las xarcias, artillería y mucha parte del leñamen [de otra galera]. [...] Era tan fuerte y bien compuesta de leñamen [una "Nao de guerra"] que ningún cañonazo la passó. [...] Y algunos Vaxeles a la Calabria, para que cargassen de leñamen para la fábrica de vnas galeras nueuas. [...] Naue Veneciana, cargada de leñamen, clauazón y otras prouisiones de guerra. [...] Hizo fletar en Venecia vna gruessa Naue cargada de leñamen y prouisiones de guerra. (Juan Agustín de Funes, Corónica de la Ilustríssima milicia y sagrada religión de San Juan Bautista de Jerusalem, Valencia, 1626, p. 374a; Segunda parte, Zaragoza, 1639 , pp. 93b, 144a, 192b, 341a y $227 a$; GB).

[1634] Cercaron luego coches la faluca, assí para ver su luzido leñamen, que era estremado, como por mirar los que venían en el vaso. (Alonso de Castillo Solórzano, Fiestas del jardín, Valencia, 1634, p. 2; GB).

De acuerdo con la documentación que hemos manejado - aquí, naturalmente, solo se citan algunos textos-, puede decirse que en el periodo que estamos considerando la forma leñame muestra tener más uso que la variante leñamen. Ahora bien, a partir de los años veinte del siglo XVII parece que quienes la usaron - que no fueron muchos - se decantaron por la forma acabada en amen. Acaso sea significativo que en la segunda mitad de dicha centuria, periodo en que la voz apenas se empleaba ya, nos encontremos con una traducción del italiano donde también se prefiere la forma leñamen, empleada hasta en cinco ocasiones:

(40) [1684] Se entretenía él en conduzir [con galeras] al sitio sacos de lana, leñamen. [...] Eran las Galeras enemigas inferiores en porte y calidad a las nuestras, assí por el verde leñamen de que estauan fabricadas como de la chusma visoña que la manejaua. [...] Seruían también [los caballos] en el transporte de las faginas, leñamen y broça. [...] Auiendo salido vna noche con pequeñas Barquillas, pusieron fuego a las faginas y leñamen, sobre el qual fabricauan en la Laguna los Christianos vna fortificación. [...] No faltan algunas casas de leñamen. (Juan Sagredo, Memorias históricas de los monarcas othomanos, trad. Francisco de Olivares Murillo, Madrid, 1684, pp. 284b, 300b, 397a y 490a; BVPB) 24.

No podemos dejar de hacer un comentario en torno al registro lexicográfico de la voz que nos incumbe. Como queda dicho, la Academia registró el sustantivo leñame en el diccionario usual de 1803, con las dos siguientes acepciones: “ant. Lo mismo que MADERA" y "ant. Mar. La provisión de 
leña". A tenor de los textos expuestos -y de otros que han sido tenidos en consideración, pero no pueden citarse aquí-, debe decirse que el valor semántico con que se emplea leñame(n) en español se corresponde con la primera acepción que incluyó la Academia. Se ha indicado que este sustantivo puede proceder tanto del catalán llenyan como del italiano legname. Para el catalán DCVB recoge los dos siguientes sentidos: "1. Conjunt de llenya o de fusta de construcció; matèria llenyosa per a construcció; cast. maderaje, maderamen"y “2. Biga; cadascuna de les peces llargueres de fusta que sostenen un sostre o teulada (Mall., Men.); cast. madero, viga”. Y en italiano legname, entre otras acepciones, tiene la siguiente: "Il legno considerato come materiale da lavoro o da costruzione, ridotto in tavole, assi, pali, travi, ecc." (GDLI: s. v.). Pues bien, con este valor, y no con otros, llegó al español la voz leñame(n); lo que queremos decir es que quienes la utilizaron en español se servían de ella para aludir al conjunto de madera empleada en construcciones (embarcaciones, casas, etc.), no a la leña para quemar. Importa subrayar, por tanto, que en español nunca se empleó con la acepción "La provisión de leña”, sentido que se perpetuó en la lexicografía académica y llega hasta la actualidad (DRAE 2014). ¿Por qué se incluyó entonces esta acepción en el diccionario de 1803? Lo más probable es que los académicos de principios del siglo XIX, época en la que como sabemos ya no se empleaba la voz leñame(n), se dejaran llevar por su competencia léxica y, a partir del valor del sustantivo leña 'madera cortada para quemar', estimaran que leñame, además de la acepción 'madera', también debió de tener el sentido colectivo 'conjunto de leña'. No fue así, sin embargo. En consecuencia, debemos considerar el sentido "Provisión de leña" (DRAE 2014) una acepción fantasma, fruto, a nuestro entender, de una errada interpretación de la voz de marras a partir de la propia competencia léxica 25.

\subsection{Maderame(n)}

La voz maderame(n) comienza a utilizarse en español en el último tercio del siglo XVI y llega con plena vitalidad hasta nuestros días (DEA: 'conjunto de maderas de una obra o construcción'). De ello dan cumplida cuenta las diversas fuentes consultadas, tanto corpus (CORDE, CNDH, CREA, DaviesE, etc.) como otras fuentes de información (Fich. Ac., GB, Archive, BVPB, HDBN, BVPH, Abc, La Vanguardia, etc.), donde pueden localizarse millares de textos. Lo realmente interesante, por tanto, son sus primeras documentaciones, su origen y el desarrollo durante su primer siglo de vida. Veamos, en primer lugar, las primeras documentaciones que conocemos de esta voz:

[1577] Hiço hacer con tanta prestesa como la ocasión lo requería vn gran puente sobre barcas y maderamen. (Pedro Cornejo, Sumario de las guerras civiles y causas de la rebellión de Flandres, León, 1577, p. [200; 198 por error]; GB).

[1588] Seluas tiene magníficas de leña, maderame y de caça. [...] Se haze casi todo el maderame de los edificios [de cierta madera]. (Abraham Ortelio, Theatro de la tierra universal, Amberes, 1588, pp. 65 y 86; Archive).

[1590] Me consta que se cobró de la dicha galera perdida todo el maderame de la popa. ("Relación del daño recibido por don Cosme Centurión por la pérdida de una de sus galeras", Génova (Italia), 1 de mayo de 1590, Archivo General de Simancas, Sección Varios Galeras, legajo 3, fol. 172; CODEA-1030). 

el río que viene de Dargau con gran cantidad de maderame, faxinas y tierra. [...] Assí está la cabeça guarnecida [de un fuerte] con gran cantidad de maderame y grosíssimas piedras. (Bernardino de Mendoza, Comentarios de don - de lo sucedido en las Guerras de los Paýses baxos, desde el año de 1567 hasta el de 1577, Madrid, 1592, fols. 251v. -, $273 v .$. - y 288r..-; GB).

(45) [1594] Estando cargadas de feno, paja, leña, o otras cosas semejantes, o maderame puesta por orden, se ha de tentar con medias picas. (Bernardino de Mendoza, Theórica y práctica de la guerra, Amberes, 1596, p. 133; Fich. Ac.).

Salvo la primera documentación (41), donde se lee maderamen, la forma que se empleaba entonces y que seguirá utilizándose durante los primeros años del siglo XVII, e incluso después, era maderame. La lexicografía española, en cambio, solo registra la variante con - $n$; ello se debe a que el Diccionario de autoridades (t. IV, 1734) recogió la forma maderamen (definida como "El conjunto de madera, que sirve para un edificio u otra cosa") basándose, de una parte, en un texto de la Historia de la conquista de México de Solís (cfr. 52) y, de otra parte, en la competencia idiomática de los académicos fundadores, propia de hablantes de español del siglo XVIII, cuando maderamen era la única forma existente. Aunque la variante más empleada en los primeros textos que conocemos fue maderame, se observaba que durante el siglo XVII esta forma fue cediendo el paso a maderamen, variante adaptada que venía a coincidir tanto con los latinismos terminados en -amen (certamen, dictamen, examen, gravamen, vejamen, etc.) como, sobre todo, con otros sustantivos con la misma terminación, con el sentido colectivo que nos atañe y que circulaban en español en tal centuria:

[46) [1610] Sirue de madera para el maderame d[e] las casas. [...] Se precian a porfía todas las parrochias y monasterios de tener dedicadas ricas camas de campo, con sus paramentos de brocados y damascos, que assí en las molduras y follajes del maderame [...]. La insigne casa de la Diputación, cuyos techos dorados de artificiosas entalladuras y maderame [...]. (Gaspar Escolano, Década primera de la historia de la Insigne y Coronada Ciudad y Reyno de Valencia, Valencia, 1610, columnas 710, 1039 y 1089; BVPB).

(47) [1611] La immortalidad de sus artezones y maderame de los techos. [...] Este autor no dixo que aquel maderame era de Torre, sino del Templo de la Diosa Diana. [...] Hecha [una torre] del mesmo pertrecho, cubierta del mesmo maderame. (Gaspar Escolano, Segunda parte de la década primera de la historia de la Insigne y Coronada Ciudad y Reyno de Valencia, Valencia, 1611, columnas 120, 381 у 382; GB).

(48) [1613] El maderamen, para ser bueno y durable, a de ser cortado en buena sazón. [...] - ¿Qué maderamen es más propio y natural para hazer afustes, Ruedas y carros y las demás cosas de todo el seruiçio del artillería, Capitán? - Todo el maderamen conuiene que sea de olmo de Roble o de nogal [...]. Si alguna parte de afuste se rompe, acomodarla y fortificarla de forma que pueda seruir como nueuo, cortar maderamen y labrarlo. [...]. La calidad del maderame [sic] [...]. 
El último puente de la presente figura muestra llanamente cómo sobre toneles o maderamen se puede fabricar vn puente ligero. (Diego Ufano, Tratado de la artillería, Bruselas, 1613, pp. 95, 96, 143, 255 y 275; GB).

(49) [1622] Sacose desto el prouecho de arrasar la campaña [...] y poder meter en la ciudad para quemar, y otros seruicios, las bigas y maderames. (Carlos Coloma, Las guerras de los Estados Baxos..., Amberes, 1625; GB).

(50) [1631] La cal y el maderamen [...]. No faltauan municiones, ni marinaje, y artilleros, ni maderamen excelente. (Gonzalo de Céspedes y Meneses, Primera parte de la historia de D. Felippe el IIII, rey de las Españas, Lisboa, 1631, p. 471b y 590a; Archive).

(51) [1639] Primeramente, hauía hecho para la dicha herrería y puesto en ella la rueda barquinero nueba, que hauía costado diez ducados y çinco reales, así el maderamen como manos. ("Memoria de obra en una herrería”, Durango (Vizcaya), 1639, Archivo Histórico Provincial de Vizcaya, sign. P-0049; CORLEXIN).

(52) [1684] Los Techos [del palacio de Motezuma] de Ciprés, Cedro y otras maderas olorosas, con diversos follages y relieves, en cuya contextura se reparó que, sin aver hallado el vso de los clavos, formavan grandes Artesones, afirmando el maderamen y las tablas en su misma trabazón. [...]. Antonio de Herrera dize que salieron de Tlascala, con el maderamen de los Bergantines, ciento y ochenta mil hombres de guerra. (Antonio de Solís, Historia de la conquista de México, población y progressos de la América septentrional, conocida por el nombre de Nueva España, Madrid, 1684, pp. $229 a-b$ y $476 b)$.

Antes de ocuparnos del origen de maderame(n) en español, debemos atender a la competencia y al relevo léxico que se produjo en relación con otras voces de la familia de madera semánticamente semejantes a aquella. Una palabra que se venía utilizando desde finales del siglo $\mathrm{XV}$, y tiene plena vigencia durante el siguiente, es enmaderamiento, de la cual Nebrija (1495) ofrece el equivalente latino que sigue: "Emmaderamiento ${ }^{26}$ assí. contignatio. onis", literalmente, 'con maderas' (cum tignum) ${ }^{27}$. A partir del siglo XVII la suerte de esta voz está unida al paulatino éxito de maderame $(n)$ : a medida que esta se difundía, la utilización de enmaderamiento disminuía notablemente. Con la voz maderamiento sucede prácticamente lo mismo: se documenta en Nebrija (1495: "Maderamiento. contignatio. onis"), se empleó sobre todo en el siglo XVI y, posteriormente, su uso fue decreciendo a consecuencia de la pujanza de maderamen ${ }^{28}$. Lo cierto es que, existiendo las palabras enmaderamiento y maderamiento, que poseían sentidos similares a maderamen, resulta llamativo que a partir del último tercio del xvi se acudiera a una nueva voz que no solo aventajó a aquellas, sino que terminó sustituyéndolas y adquiriendo una difusión extraordinaria en español. ¿Acaso podría hablarse de una moda que privilegió durante un tiempo las voces foráneas en - $\operatorname{ame}(n)$ frente a los sinónimos oriundos del español?

Atendamos ya al origen de maderame(n). A juzgar por la documentación que conocemos hoy día, carece de validez la hipótesis de Corominas que vincula la voz maderamen —única variante que conoce el etimólogo - con el vasco: "La emplea Azkue muy a menudo en las definiciones de su dicc. [Diccionario vasco-español-francés, 2 vols. Bilbao/París, 1905-1906] y supl. vascos (en zuraje y zubaje 'conjunto de maderas de un edificio, charpente' y otras varias palabras), de suerte que 
debe de ser vivo también en el castellano vascongado", y más adelante afirma que no es imposible "que tengamos ahí una alteración de maderamiento oriunda del País Vasco". Descartada esta vinculación, tenemos, por tanto, que atender a otras vías.

Tanto el gallego como el portugués conocen el nombre madeirame(n); sin embargo, estas lenguas, por cuestiones cronológicas, no pudieron ser las que proporcionaron la voz al español, sino que más bien sucedió lo contrario. El portugués, que prefiere el término madeiramento (" $O$ madeiramento das casas; toda a madeira com que ella se arma dos frechaes para cima"; Silva 1831: s. v.; cfr. DICIweb), tomó del español el nombre maderame, que con las adaptaciones oportunas pasó a ser madeirame, documentado desde principios del siglo XIX (53) ${ }^{29}$. Hay que indicar, no obstante, que ni Silva (1831) ni Faria (1852) recogieron madeirame en sus diccionarios, mientras que sí incluyeron madeiramento ${ }^{30}$. Por su parte, en gallego, donde la voz madeirame tiene escaso uso (cfr. TILG y Galiciana), se documenta por primera vez la forma madeiramen a finales del mismo siglo, lo que hace pensar que el término procede, como sugiere la presencia del fonema nasal final, del español maderamen y no del portugués madeirame (cfr. 54 y 55). Con todo, a partir de Vocabulario popular galego-castelán (1926) de Filgueira Valverde et al., la lexicografía gallega prefirió codificar, en consonancia con la morfología de esta lengua, la forma madeirame (cfr. DdD).

(53) [1813] Lisboa, onde existia no estaleiro já embalisada huma Náo, para cuja construcção ainda não estava cortado o resto do madeirame. (José Maria Dantas Pereira, Elogio histórico do Senhor D. Pedro Carlos de Bourbon e Bragança, Infante de Hespanha e Portugal, Almirante general da marinha portugueza, Río de Janeiro, 1813, p. 17; GB).

(54) [1880] Cando estrala o madeirámen / y-a chuvia os vidros azouta [...]. (Valentín Lamas Carvajal, Saudades gallegas, versos de -, Orense, 1880, p. 61; TILG).

[1904] Se defender d'elas que en folerpas de salitrosa escuma desfasen no madeiramen da otra morta sin dañar o interior. (Revista Gallega. Semanario de Literatura é Intereses Regionales, 8 de mayo de 1904, p. 1c; HRAG).

No puede hablarse tampoco de un catalanismo, puesto que en esta lengua el colectivo empleado (desde el s. XIV; cfr. DCVB, CICA, Faraudo) es fustam, derivado de fusta 'madera' (lat. FUSTIS 'palo'). Aun así, Pharies (2002: 396) sugiere un posible modelo catalán en la formación de maderamen. Si bien este autor no menciona la voz fustam, afirma que "es posible que palabras catalanas como éstas [barrilam, botam y velam] hayan servido luego de modelo para derivaciones españolas en -amen, como maderamen 'conjunto de madera'”.

A nuestro juicio, son dos los factores que coadyuvaron a la formación de maderamen. En primer lugar, creemos que, efectivamente, puede hablarse de la influencia del catalán fustam, en el sentido de que podría haber impulsado, proyectando su estructura, la creación de una voz semejante en español: en tal caso, la base léxica catalana fusta sería sustituida por el término equivalente en español (madera) y, como sucede con otras voces morfológica y semánticamente semejantes, primero se utilizó sin el fonema nasal implosivo (maderame) y, posteriormente, con él (maderamen). Sin embargo, más importante que el factor inductor foráneo nos parece la actuación del sinónimo español leñame (cfr. § 3.3). Este préstamo debió de actuar como elemento catalizador 
en la creación maderame. De acuerdo con lo dicho más arriba, la voz leñame, a pesar de lo que pudiera pensarse en un primer momento, no significó en español 'conjunto de leña', sino que con ella se aludía al conjunto de madera con que se llevaban a cabo diversas construcciones, desde casas hasta barcos; se trataba, al fin y al cabo, de un valor semántico procedente de los sustantivos homólogos extranjeros (cat. llenyam y/o it. legname). Pues bien, si leñame, junto con el modelo estructural de fustam, había propiciado la formación interna de la voz maderame, el desenvolvimiento y la difusión de esta última supusieron a la postre el golpe de muerte de aquel nombre: el uso de leñame fue decreciendo paulatinamente como consecuencia del éxito de la creación inducida maderame(n), término que, al acoger con mayor naturalidad el significado de leñame, terminó triunfando en el español del siglo XVII y continuó empleándose en los sucesivos.

\subsection{Poleame(n)}

Al referirse al sufijo -ame, Alemany (1920: 17) afirma que procede "Del mismo origen que AMEN, por pérdida de la $n$ " y, seguidamente, lo ejemplifica con algunos nombres que considera "de formación castellana, como el ant. bestiame, de bestia; leñame, de leña; poleame, de polea" (§§ 3.2 y 3.3)31. El nombre poleame 'conjunto de poleas de una embarcación' se documenta en español desde la primera mitad del siglo XVI:

(56) [c1519] 6 Broznos para poleas y una polea de broznos. / 3 Gurbias. / Poleame. 3 Cucharas para brea. / Sacos de cáñamo para el servicio de la naos. / 8 Sierras grandes y pequeñas. / Escoperos para embrear y ensebar. / Jarcia. / 417 Pipas para el vino y agua. / 253 Botas para ídem. / 45 Toneles para ídem. / Vasijas para el aceite. / 129 Botijas para el vinagre y otras cosas. / Barriles para los quesos. ("De la habitación que tuvo y viage que hizo la Armada del Emperador Carlos v, de que era Capitán general Fernando Magallanes [...] emprendido desde S. Lúcar de Barrameda el año 1519 al descubrimiento por el O. de la islas Molucas", ed. Martín Fernández de Navarrete, Colección de los viages y descubrimientos que hicieron por mar los españoles desde fines del siglo $\mathrm{XV}$, con varios documentos inéditos concernientes a la historia de la marina castellana y de los establecimientos españoles en Indias, Madrid, t. IV, 1837, p. 7; Archive).

(57) [c1519] Treinta y cuatro mil seiscientos setenta y dos maravedís y medio que ha costado el poleame que lleva la dicha Armada. (Relación del coste que tuvo la Armada de Magallanes, [Arch. de Ind. en Sevilla, papeles del Maluco, leg. 1.o de 1519 a 1547], ed. Martín Fernández de Navarrete, Colección de los viages y descubrimientos que hicieron por mar los españoles desde fines del siglo $\mathrm{xv}$, con varios documentos inéditos concernientes a la historia de la marina castellana y de los establecimientos españoles en Indias, Madrid, t. IV, 1837, p. 165; CORDE).

(58) [1521] 25 remos nuevos, y demás la madera labrada en pieza para un navío, y poleame para tres navíos. (Colección de documentos inéditos relativos al descubrimiento, conquista y organización de las antiguas posesiones españolas en América y Oceanía, Madrid, t. XIV, 1870, p. 10; GB). 
Es muy escasa la documentación de voz poleame en español. Los textos citados son los únicos que hemos podido allegar para el siglo XVI. Posteriormente, se produce un vacío en la documentación y no vuelve a aparecer en los textos hasta el siglo XVII. Después de esta centuria pese a que puede encontrarse de manera aislada en algún otro texto- deja de utilizarse en español ${ }^{32}$.

(60) [1631] Puede el capitán, si lleva alguna posaverga, jarcia, belas, poleame u otras cosas de consideración [...]. (Tomé Cano, Diálogo entre un Bizcaýno y un Montañés sobre la fábrica de navíos, 1631, fol. 29r.;ㅜ CORDE).

(61) [1633] En la misma Junta se hará otra Relación del Poleame, Clavazón y demás Pertrechos que los Navíos huvieren de llevar de respeto, porque en la Mar no se hallen con falta de cosas tan necessarias. [...] Las Tassaciones de la Madera, Poleame, Clavazones y demás cosas que se gastan la hará el Capitán de la Maestranza. (Ordenanzas para el govierno de la Armada Real del Mar Océano, despachadas por Su Magestad Cathólica en Madrid a 24 de enero de 1633, ed. Joseph Antonio de Abreu y Bertodano, Colección de los tratados de paz, alianza, neutralidad..., Madrid, 1745, pp. $436 b$ y 431b; Fich. Ac.).

(62) [1639] Todo el poleamen y racamentto ba dorado y el costado breado asta la lumbre del agua. (Doc. que comienza “Digo yo, el capitán Lucas Guillén de Beas, vezino desta ciudad de Sevilla [...]", en la data 15 de febrero de 1639, ed. José Gestoso y Pérez, El navío "El Santo Rey D. Fernando". Memorias históricas sevillanas del siglo XVII, Sevilla, 1890, p. 21; Archive).

(63) [1671] Mucha partida de fierro tocho para las áncoras y de jarcias y poleamen y todos los quadernales nezesarios para el bote. ("Información sobre el estado de la fábrica de los galeones asentados con Pedro González de Agüero en mayo de 1671", ed. Miguel Cisneros Cunchillos et al., El astillero de Colindres (Cantabria) en la época de los Austrias menores. Arqueología y construcción naval, Santander, Universidad de Cantabria/Ayuntamiento de Colindres, 1997, p. 181; GB).

Es manifiesto que se trata de una voz foránea: la terminación no patrimonial de la variante poleame lo denuncia. Esta forma siguió utilizándose en el primer tercio del siglo XVII (60 y 61); sin embargo, junto a poleame, también comenzó a emplearse en ese mismo periodo la variante 
poleamen, que se asimiló, con un incremento fonológico nasal, a los latinismos que circulaban en la época y, sobre todo, a otros nombres colectivos que a la sazón se empleaban con la terminación -amen (cfr. velamen, bestiamen, leñamen y maderamen en §§ 3.1-3.4). Por tanto, no estaba en lo cierto Alemany al proponer que se trataba de un nombre "de formación castellana" que había perdido el fonema nasal final, sino que estamos ante un préstamo que primero se empleó en español con la forma poleame y solo más adelante adquirió, y no en todos los casos, dicho fonema.

El término procede del portugués, lengua en la que está ricamente documentado, sobre todo a partir de finales del siglo XVI ${ }^{33}$. DCECH (s. v. polea) señala que se trata de un lusismo: "Poleame [1519, Woodbr.], tomado del port. poleame íd.". En efecto, en portugués la voz náutica poleame tiene el sentido "O apparelho de polé, e roldanas, e cordas, para levantar pesos, içar, etc." (Silva 1831: s. v.). Sin embargo, debemos confesar que no nos ha sido posible documentar la voz en portugués antes de 151934, fecha en la que ya la encontramos en español (cfr. 56-57) ${ }^{35}$. Con todo, es clara la vinculación con esta lengua, tal y como lo ponen de relieve los textos 56 y 57, donde se da cuenta de algunos de los pertrechos marítimos de que se sirvió el portugués Fernando de Magallanes para los viajes que llevó a cabo bajo el servicio de Carlos v. Bluteau recoge en su Vocabulario português e latino (1712-1718) la voz poleame, de la que afirma: "chamão os homens do mar às Polés, necessarias para a mareação de hum navio. Trochleae navales, Plur."; seguidamente, cita un texto de los Apologéticos discursos (1641) de Luís Marihno de Azevedo: "Todos os cabos de serviço, \& Poleame". Aún más importante es la documentación que, de manera telegráfica, recoge el Diccionario da lingua portugueza (1831) de Silva: "F. Mend. c. 58. Chron. J. III. P. 4. c. 118. "officiaes de poleame" que o fazem. Couto, 6. 8. 5". Hechas las pesquisas necesarias, los textos aludidos son los que se citan a continuación con los números 65, 66 y 67; a estos textos hemos podido allegar otro, de 1541, del historiador portugués Gaspar Correia (1495-1561):

[64) [1541] Estaua carregada [una nave] d'entenas, e mastos de pinho muy bons, e muyta enxarcea de linho, e muyto poleame embroçado. (Gaspar Correia, Lendas da Índia, ed. Rodrigo José de Lima Felner, Lisboa, t. IV, parte I, 1864, p. 186; GB).

[65) [a1583] Vergas, pavezes, entenas, calhau, poleame, driças, ancoras. (Fernão Mendes Pinto, Peregrinação, a1583, ed. J. I. de Brito Rebello, Lisboa, 1908, vol. I, p. 17336; GB).

(66) [1597-1598] A dom Ioaõ de Mendoça deu os officiaes de poleame. (Diogo de Couto, Década sexta da Asia, Lisboa, 1614, fol. 143v.ํ37; GB).

(67) [1613] Recolherão toda a enxarcia \& poleame. (Francisco de Andrada, Cronica do muyto alto e muito poderoso Rey destes Reynos de Portugal Dom Ioão o III.

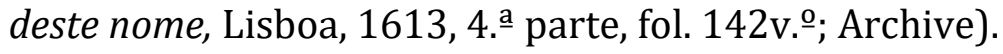

\subsection{Cordame(n)}

El siguiente sustantivo del que debemos ocuparnos es cordame(n), término que no ha dejado huella en la lexicografía española. Veamos los textos en los que documentamos esta voz: 
(68) [1613] Seguirán todas las municiones y aparatos de guerra [...], con todo el cumplimiento de la maestrança y estado del artillería y con todas suertes de cordames y clauazón y todo lo demás que deue seguir al train del artillería, con todos sus elementos y montages.

[...] El almirante de aragón passó en frisa con el exérçito de Su Mag. d, siendo Capitán general del artillería Don Luis de Velasco, que lleuaua en su traén vn puente muy largo hecho de troços de tela muy fuerte sobre vna xareta de cordame enbastado y sus tirantes de madera ligera muy bien façionado.

[...] También de cada lado se le podrá hazer vna baranda de pilaretes de madera bien clauada y cordamen para que ninguna cosa ni gente pueda caer del puente abaxo dentro del agua. (Diego Ufano, Tratado de artillería, Bruselas, 1613, pp. 106, 2[69] y 275; Fich. Ac.; cfr. DICTER 2, s. v. cordamen).

(69) [1639] Taeckelen de schepen / armar los bajeles con el cordamen, encordelar los bajeles. Taeckelinghe / cordamen de vn bajel, armazón, armadura de vn bajel. (El grande dictionario y thesoro de las tres lenguas Española, Francesa y Flamenca, con todos los nombres de los Reynos, Ciudades y lugares del Mundo, Amberes, Caesar Joachim Trognesius, 1639; GB).

(70) [1669] Se pueden fabricar [unas alas de una barca] de tela cruda muy bien bandada y tirante, sobre cordame fuerte, para que sin romper pueda sufrir el peso de los que han de passar por ensima. (Alonso de Zepeda y Adrada, Epítome de la fortificación moderna, Bruselas, 1669, p. 309; GB).

(71) [1687] Barcas si el fosso es de agua y ay poternas, brea, estopas, cordamen, lampiones en palos largos. (Sebastián Fernández de Medrano, El ingeniero. Primera parte de la moderna architectura militar, Bruselas, 1687, p. 284; GB).

(72) [1688] Por todas estas Islas y su cercanía, en tierra firme, se abunda de toda Specería, cosas Aromáticas, açúcar, Algodón, y piedras preciosas, y en muchas de un Árbol cuyo fruto maduro les es vianda; verde y exprimido, beuida; de las cortezas se haze lino y cordamen; y del tronco, casas, nauíos y fuego. (Sebastián Fernández de Medrano, Breve descripción del mundo o guía geográphica, Bruselas, 1688, p. 74, n.; CORDE; cfr. texto 80, que es la 1.ㄹ ed. de esta obra).

(73) [1700] Pasa [el río Marañón de Perú] cortando el camino real de las dos nombradas Villas Guanuco y Guamango, comunicándose estas por un puente que sobre dicho río hay de madera y cordamen, ingeniosamente fabricado. (Sebastián Fernández de Medrano, Breve tratado de geographía, Bruselas, 1700, p. 30; GB).

Además del español, hay tres lenguas romances que conocen la voz que nos interesa: el catalán, el italiano y el portugués. Debe descartarse, en primer lugar, el portugués como lengua prestadora, pues la incorporación de cordame en ella es bastante tardía: según Cunha (2010: s. v. corda) se produjo a mediados del siglo XIX (1844); téngase en cuenta que se documenta desde el siglo XV (Cunha 2010: ibíd.) el sinónimo cordoalha "o apparelho de cordas, cabos, calabres, amarras para o 
uso de um navio ou de navios, ou sejam feitas de cânamo, linho, cairo, algodão, ou esparto" (Faria 1851), de gran difusión en portugués.

En catalán, en cambio, el nombre cordam se documenta muy temprano. DCVB ofrece dos testimonios de finales del siglo XIII y otro del XVI: "Conjunt de cordes (en general); cast. cordelería [cfr. n. 44]. Càrrega de cingles execurs, o de cordam, doc. a. 1288 (RLR, IV, 508). Que negú no sia ausable de vendre dins Perpenyà cordam negú ni singles de camge botatz, doc. a. $1296(R L R, \mathrm{~V}, 93)$. Setze peces de cordam prim e gros, doc. a. 1527 (arx. parr. de Sta. Col de Q.)". Exceptuando el tercer texto recogido en DCVB, la documentación disponible para los siglos XVI y XVII es prácticamente inexistente. En este sentido, resulta significativo que DECat ofrezca varios textos de los siglos XIII y XIV y, seguidamente, aporte un testimonio de la segunda mitad del XIX: "NOller, Croquis, 110". Se trata de la obra Cróquis del natural (1879), de Narcís Oller38 (también citada en Diccionari Balari, s. v. cordam; cfr. Faraudo). Esta discontinuidad en la documentación catalana de cordam viene a confirmarse al consultar otras fuentes, como CICA, que no ofrece texto alguno con dicho sustantivo. (Para el siglo XIX y, sobre todo, el XX, puede consultarse CTILC y DDLC).

Además de lo indicado, hay motivos para que nos inclinemos, con la debida precaución, por la procedencia italiana ${ }^{39}$. Son escasos los testimonios españoles que nos han llegado de cordame(n), pero lo cierto es que presentan ciertos rasgos comunes que parecen sugerir aquella etimología. Por de pronto, se trata de textos que fueron publicados en los "Países Bajos españoles" y, sobre todo, en Bruselas, lo que nos conduce a una zona geográfica determinada y a un contexto histórico concreto. Además, importa destacar que, a excepción del testimonio 69, formado por dos entradas de El grande dictionario y thesoro de las tres lenguas Española, Francesa y Flamenca (1639), los demás textos fueron escritos por militares o ingenieros militares españoles que en cierto periodo de su carrera fueron enviados a Flandes, lo que seguramente supuso que recorrieran el denominado "Camino español" o "Camino de los tercios españoles" para alcanzar suelo de los Países Bajos, un corredor militar que conectaba Milán con Bruselas y con el que se evitaba el recorrido por Francia y la navegación por el Canal de la Mancha, acechado por la armada británica e infestado de piratas ${ }^{40}$. No obstante, no solo importa el contacto que tales ingenieros militares debieron de tener con la lengua italiana, sino fundamentalmente el más que probable conocimiento de los diversos tratados bélicos que se habían escrito en esa lengua, donde precisamente se utilizaba la voz cordame (cfr. 74-76).

A juzgar por la documentación textual que exhibe el GDLI, se podría pensar que los textos españoles se adelantan cronológicamente a los italianos, lo que desde luego supondría un problema para esta propuesta etimológica. Para la acepción "Marin. Il complesso delle corde di una nave usate nelle operazioni di manovra e di ormeggio; corredo di corde di riserva" el GDLI ofrece, entre otros, dos textos del último tercio del siglo XVII: una traducción de Filippo Corsini (Istoria della conquista del Messico scritta in castigliano da Antonio de Solis, 1669) y un texto de Lorenzo Magalloti (Della palma: sue varietà, frutto, utilità e coltura, a1693) ${ }^{41}$. Ahora bien, si se consultan otras fuentes, es posible documentar en italiano el término cordame desde finales del xVI y, además, lo que es más importante para nuestro propósito, se utilizó en distintos tratados militares que muy probablamente conocían y manejaron los ingenieros españoles que desarrollaron gran parte de su carrera militar en Bruselas. Algunos de los textos a que nos referimos son los siguientes:

(74) [1572] Cordami di gomoni di Gallee grosse - n. 5 / Cordami di prouan di Galee grosse - n. 6 / Cordami di fusta di Galea sottile - n. 4 / Cordami di canal di 
Galea grossa - n. 4. (Girolamo Ruscelli, Precetti della militia moderna, tanto per mare, quanto per terra, Venecia, 1572, fol. 13r..; GB).

(75) [1586] Il presente auuertimento sarà a tutti li Bombardieri generalmente, come sono obligati, non solamente a conoscer tutte la ferramenta, guernimenti, \& altri vtensilij dell' arteglieria, sì de' legnami, ferro, \& cordami, \& altre cose, che per vso, \& seruitio di essa si conducono nell'impresa, ma sono etiandio obligati di hauerle tutte nella memoria, \& saperle nominare tutte ad vna per vna [...]. (Luis Collado, Pratica manuale di arteglieria, Venecia, 1586, fol. 13v. - ; Archive ${ }^{42}$ ).

(76) [1640] Delle robbe, che fano bisogno per la sopradetta Artegliaria, si cordami per tirarla come Letti, Rote, \& nassi con altri apprestamenti. Cap. VII [...]. \& assenone per poterla Caualcare, \& li animali, \& cordami per tirrarla con prestezza [...]. Ma sempre stijno assistenti con li animali, \& cordami [...]. Sei, ouer orto beri, per la' Artegliaria. Cordami per tirar la detta, come di sopra. (Camilo Zonta Padouano, Capitan d'artegliaria, opera non ancora d'altro autores trattata, Venecia, 1640, pp. 5, 14, 20 y 48; GB).

(77) [1662] Cordagili, \& cordame] cordages. (Nathanael Duez, "Maistre de la Langue Françoise, Italienne, \& Allemande", Dittionario italiano, et francese. Dictionnaire italien et francois, "premiere partie", Venecia, 1662; GB).

De acuerdo con lo dicho, parece razonable pensar que el italiano pudo ser la lengua que propició los escasos testimonios de cordame(n) que conocemos en español. ¿Qué impidió, entonces, que dicho préstamo se afianzara en esta lengua e hizo que quedara reducido prácticamente a los citados textos del ámbito militar? La respuesta debe buscarse en la existencia de otras voces sinónimas que el español del siglo xviI tenía, o comenzaba a tener, y que hicieron innecesaria la importación de un nuevo término. Una de estas palabras es el sustantivo de procedencia francesa cordaje. Aunque $D C E C H$ (s. v. cuerda) documenta esta voz en 1709 (Thomás Vicente Tosca), una vez más las diversas fuentes consultadas permiten constatar que cordaje - normalmente con la grafía galicista cordage - se utilizaba desde el siglo xvi; uno de los autores que la emplearon fue, precisamente, Fernández de Medrado, que en 1686 escribía cordage (80) y, posteriormente, se decantaba por cordamen (71-73).

(78) [1569] Otro hizo vna nao con todos sus aparejos, velas, cordages y xarcias, tan grande que la cubría vna aueja las alas. (Baltasar Pérez del Castillo, El theatro del mundo ${ }^{43}$, Alcalá, 1564, fol. 139v.o; GB).

(79) [1653] Suelen traer de España algunas jarcias, pero ahora en menos cantidad que antes, a causa de que se labra ya en Chile mucho Cáñamo, de a donde se traen jarcias y toda suerte de cordaje al puerto desta ciudad de Lima. (Bernabé Cobo, Historia del nuevo mundo, Sevilla, t. II, 1891, p. 419; Fich. Ac.).

(80) [1686] Son muy estériles [las islas "Maldivias"] y solo tienen un árbol, cuyo fruto, estando maduro, sirve de vianda; y verde y esprimido, de bevida; de sus cortezas se haze lino para lienzo y cordage; y del tronco, casas, navíos y fuego. (Sebastián 
Fernández de Medrano, Breve descripción del mundo y sus partes o guía geográphica y hydrográphica, Bruselas, 1686, p. 204; GB).

Existen otros sustantivos, más o menos sinónimos, que se documentan antes de la aparición cordame(n) y que de algún modo pudieron desaconsejar la incorporación de tal voz ${ }^{44}$; ahora bien, en el ámbito náutico, la voz que realmente impidió que prosperara el italianismo fue jarcia(s) ("Primitivamente significa los aparejos y cabos del navío. Úsase freqüentemente en plural", Autoridades, t. VI, 1739: s. v. xarcia), cuyo uso, bien asentado en español, se remontaba a la Edad Media.

\subsection{Botamen}

Las primeras documentaciones en español de botamen 'pipería' se encuentran en varios escritos de Hernán Cortés. El primer texto (81) pertenece a una de las conocidas "cartas de relación”, una suerte de largos informes oficiales en los que Cortés narraba al emperador Carlos $\mathrm{V}$ diversos episodios de la conquista de México; el segundo texto (82) se encuentra en otra carta dirigida al mismo monarca, en la que Cortés da cuenta de la exploración y descubrimiento de las costas del Pacífico. El tercer testimonio (83) es un texto que pertenece al ámbito del conquistador extremeño, pues Francisco de Ulloa fue un capitán que participó en las expediciones a California organizadas por Hernán Cortés en 1535 y 1539:

[1524] El puerto donde los dichos navíos se hacen todo el adereszo que para ellos era menester de velas, cables, jarcia, clavazón, áncoras, pez, sebo, estopa, botamen, aceite y otras cosas [...]. Podrán navegar [los navíos] si botamen no me falta, porque como se quemó lo que tenía no he tenido de dónde proveerme. (Hernán Cortés, Cartas de relación, ed. Ángel Delgado Gómez, Madrid, Castalia, 1993, pp. 499 y 500; GB).

[1533] Impedirme el acarreo de bastimentos y botamen que tenía para el viaje. (Cartas y relaciones de Hernán Cortés al Emperador Carlos $V$, colegias e ilustradas por don Pascual de Gayangos, París, 1866, pp. 521-522; GB).

[1540] Metimos en la [nao] Trenidad, porque se metía más al cabo e iba todo el botamen vazío, e toda la gente de mar en tierra era nescesaria para tomar el aguada. (Francisco de Ulloa, Relación del viaje que hizo el capitán -, por orden de Hernán Cortés, por la costa de Nueva España, desde Acapulco hasta la Isla de los Cedros, y las posesiones que tomó en nombre del mismo Cortés, en Relaciones históricas de América. Primera mitad del siglo XVI, Madrid, 1916, p. 229; Archive).

[1681] Los Navíos vayan bien marinenerados [sic, error por marinerados] de Pilotos, Marineros, Grumetes y Pages, cuantos fueren necessarios al porte del Navío, con los aparejos convenientes, assí de velas como de anclas, y botamen, y estancos de agua, y proveídos de las armas necessarias para defenderse y ofender a los enemigos. (Recopilación de leyes de los reynos de Las Indias, Madrid, 1681, t. IV, 18v.; GB). 
Hay que decir que este sustantivo no tuvo éxito en español. Son muy escasos los textos en que ocurre la voz botamen; como vemos, parece que tuvo alguna circulación en la primera mitad del XVI y, posteriormente, dejó de emplearse. A juzgar por la documentación disponible, el texto de 1681 debe considerarse un empleo extemporáneo de dicho nombre. Pese a la escasa documentación disponible, botamen se encuentra en toda la lexicografía académica y en otros muchos diccionarios. Ello se debe a que en el siglo XVIII cayó en las manos de la Academia el texto citado de la Recopilación de leyes (1681) y se recogió la voz botamen en Autoridades (t. I, 1726): "Número grande y cantidad de botas de madera para proveer los navíos" (en Auts. 1770 con marca de voz náutica) ${ }^{45}$.

$D C E C H$ (s. v. bota I) indica que botamen procede "del cat. botam, colectivo de bóta" 46. Según $D C V B$, el colectivo botam se documenta en catalán en 1311: "Tot hom qui fassa vaxels botam o miganes de royre en los boschs" (DECat recoge otro testimonio de c138047). No debe descartarse, sin embargo, la influencia del italiano, puesto que en esta lengua, según TLIO, el sustantivo bottame data también del siglo XIV:

[c1339-1340] Bottami e botti disfatte e legate in fascio con corda, una per uno cantaro di cotone. Bottame 15 disfatte e infasciate e non legate per uno cantaro di cotone. (Francesco Pegolotti, La pratica della mercatura, ed. Della decima e delle altre gravezze, $\mathrm{t}$. III, Lisbona/Lucca, 1766, p. 155; TLIO ${ }^{48}$ ).

Es probable que, antes de la forma botamen, tuviera algún uso en español la variante semiadaptada *botame, tal y como sucedió con otros nombres semejantes que comenzaron su andadura en el siglo XVI (§§ 3.1-3.5), pero la escasísima documentación que nos ha llegado en este caso no permite, sino que nos movamos en el terreno de la mera hipótesis.

\subsection{Barrilamen}

Al igual que ocurre con botamen, las fuentes primarias de que disponemos del sustantivo barrilamen 'barrilería' son exiguas:

[1614] [Proveerse] de los unos, los mantenimientos, y de los otros, gente, pólvora, armas, munición, jarcia, brea, alquitrán, vasijas y barrilamen. (Agustín de Horozco, Discurso historial de la presa que del Puerto de la Maamora hizo el Armada Real de España en el año de 1614, ed. Madrid, 1855 [BAE, XXXVI], p. 216a; DHist.).

[1639] Echando de ver el Comendador Maldonado que aquel vaxel huýa también de los Gelues, acabó de hazer su aguada, recogió su gente y la que auían dexado las otras galeras, con todo el barrilamen, y con las tres galeras de la Religión llegó a Malta [...]. Siguiéronles hasta las proas de las mismas galeras [...]; fracassáronles gran parte del barrilamen, que hallaron en tierra. (Juan Agustín 
de Funes, Corónica de la ilustríssima milicia y sagrada religión de San Juan Bautista de Jerusalem. Segunda parte, Zaragoza, 1639, pp. 420b y 628a; GB).

$D C E C H$ (s. v. barril) ofrece la siguiente información: "Barrilamen 'conjunto de barriles' [en el viajero Fr. Agustín Horozco, h. $1600^{49}$ ], barrilame (Ac. ya 1884), del cat. barrilam, colectivo de barril'. DCVB registra la voz, pero no aporta documento alguno (cfr. Escrig y Martínez 1887: s. v. barrilam). Jal (1848) recoge barilam (variante catalana de barrilam) e indica que es una voz perteneciente al catalán antiguo ("cat. anc. s. m. (De Barile) L'ensemble des tonneaux et barils d'un navire") ${ }^{50}$. Faraudo, en su Vocabulari de la llengua catalana medieval, parece confirmar que la voz tuvo algún empleo remoto, si bien únicamente cita el siguiente texto, sin datación, del "Gloss. Naut. a Taraçana": "Item, fon pagat a iij homens qui meteren lo barilam en la Taraçana, ço es a cascun VI den. I s. VI".

Aunque es posible que estemos ante un catalanismo, tampoco debe desestimarse en este caso la influencia italiana en la "penetración" de la voz barrilamen en español. Téngase en cuenta que Agustín de Horozco estuvo al servicio de Diego Hurtado de Mendoza, quien fue diplomático en Italia durante trece años. Agustín de Funes, por su parte, menciona en su Corónica hechos que acaecieron, entre otros lugares, en Malta. Además, es muy posible que para componer su obra Funes recurriera a la del turinés Giacomo Bosio, quien había empleado el sustantivo barilame en dos ocasiones en Dell'istoria della sacra religione et ill. ${ }^{m a}$ militia di San Giovanni Gierosolimitano (74). Ninguna documentación ofrece el artículo barilame de GDLI: "sm. Quantità di barili. = Voce formata secondo il tipo pellame, cuoiame, scatolame, ecc." (DELI no se ocupa de barilame); sin embargo, el GDLI recoge bajo el artículo stóppa un texto de principios del siglo XVII que contiene la voz que nos interesa: "Non mettendo... nel gavone di proda altro che stoppa da calafattar poche tavole e vimini d'acconciare il barilame" (Bartolomeo Crescènzio, Nautica mediterranea, 1607; GDLI). En el "Vocabolario nautico" de Pantera (1614) se incluye barilame: "è l'vniuersità de i barili". A estos dos testimonios se pueden añadir los dos siguientes textos de la mencionada obra de Bosio:

[1602] Buon'acqua, portandola co'l barrilame [sic]. [...] Il Barilame dell'acquata. (Giacomo Bosio, Dell'istoria della sacra religione et ill.ma militia di San Giovanni Gierosolimitano, parte terza, Roma, 1602, pp. 428 y 702).

Si dejamos al margen el registro lexicográfico español de las variantes barrilame y barrilamen ${ }^{51}$, lo cierto es que en la documentación textual de que disponemos solo constatamos la existencia de la segunda forma. Mientras que en el apartado anterior presumíamos la existencia, no documentada, de la variante *botame, en el caso de la voz que nos ocupa no resulta necesario proponer una posible forma *barrilame. Téngase en cuenta que la escasa documentación que nos ha llegado (tan solo dos textos) pertenece al primer tercio del siglo XVII; ello conduce a pensar que es plausible que, cuando se tomó el catalanismo barrilam o el italianismo barilame, el préstamo experimentara una adaptación fonética tomando como modelos otros colectivos en -amen que a la sazón, en el siglo XVII, ya circulaban. Nótese que casi todos los colectivos que presentan una forma en -ame parten del siglo XVI, mientras que los nombres barrilamen, cerdamen y pelamen solo se documentan en la centuria siguiente. 
El fracaso en español de barrilamen - y, en realidad, también de botamen $^{52}$ - encuentra su explicación en la manifiesta preferencia de los hablantes por el plural barriles; a ello se suma, sin duda, que en la época tenían alguna circulación sustantivos sinónimos como barrilería, botería y, sobre todo, pipería ${ }^{53}$ :

(89) [1583] Que la dicha armada vaya bien y abundantemente proveída de aguada limpia y buena y conservadera, y que esta se haga en pipería limpia. (La conquista de las Azores en 1583, ed. Cesáreo Fernández Duro, Madrid, 1886, p. 371; CORDE).

(90) [1583] Se sabe que de Bizcaya se puede proueer de todas las cosas de hierro, y azero, y armas. Y de Asturias, de Tabla y Madera, y Duela, y Arcos para botería y Barrilería. (Bernardino de Escalante, Diálogos del arte militar, Sevilla, 1583, fol. 166v.o; Fich. Ac.).

(91) [1623] Señala a cada nauío las toneladas que ha de tener, gente de guerra y ministros para su mejor seruicio, bastimentos, artillería, pipería. (Gil González de Ávila, Teatro de las grandezas de la Villa de Madrid, 1626, p. 516a; GB).

[1628] Se despacharon los pataches i caravelas con la pipería para hazer aguada en el río de Sanctiago. [...] A diez llegó la pipería llena i se repartió por la Armada. (Tomás Tamayo Vargas, Restauración de la ciudad del Salvador i Baía de TodosSanctos, en la Provincia de Brasil, Madrid, 1628, fols. 89v.ํy 90v.; GB).

\subsection{Cerdamen}

En 1887 el escritor y feroz crítico Antonio de Valbuena, oculto bajo el seudónimo "Miguel de Escalada", se burlaba agriamente de muchos de los artículos que contenía la duodécima edición del diccionario usual (1884). En uno de estos artículos escribía: “¿Y el cerdamen? No digo que, como de madera se forma maderamen, no se pudiera formar de cerda cerdamen, pero no se ha formado. Como no se ha formado papelamen tampoco" (El Imparcial, 18 de julio de 1887, p. 1 a; HDBN) ${ }^{54}$. Unos días más tarde recibía la réplica en un artículo firmado por Quintilius, seudónimo detrás del cual se hallaba el académico de la Española Francisco A. Commelerán; este, con algo de zumba, respondía: "La afirmación no puede ser más terminante y redonda, como del ínclito Blas; mas es el caso que de cerda podrá no haberse formado cerdamen, pero en la Vida y hechos de Estebanillo González se lee 'Hallé pegado a él todo el bigote del tal hidalgo, que era tan descomunal que podría servir de cerdamen a un hisopo'” (El Liberal, 25 de julio de 1887, p. 2 b; HDBN; cfr. 93) ${ }^{55}$. ¿Quién tenía la razón en este particular? Puede decirse que ambos en parte estaban en lo cierto. Tal y como señala Commelerán, no cabe duda de que se había formado en español la voz cerdamen, y prueba de ello es el texto que adujo el académico, tomado sin duda del Diccionario de autoridades (t. II, 1729: s. v. cerdamen "Manojo de cerdas, atado para vender o compuesto para algún uso o ministerio"). Sin embargo, las palabras de Valbuena ("no se ha formado") no carecían de sentido, si se entiende que con ellas el crítico quiso expresar que el nombre cerdamen no forma parte, stricto sensu, del léxico español, en tanto que no es una voz de lengua, sino que es un acto de habla, una creación léxica ocasional del autor del Estebanillo González. Consultadas diversas fuentes (cfr. CORDE, CNDH, CREA, Fich. Ac., HDBN, etc.), se constata que cerdamen es un ocasionalismo que no ha 
tenido fortuna en español. Sucede, por tanto, que el académico fundador encargado de la papeletización de la novela picaresca se topó con dicha voz $-\mathrm{y}$ con pelamen, de la que nos ocuparemos a continuación-, propuso su ingreso en el diccionario y obtuvo el beneplácito de la Corporación. A partir de entonces, y sin marca alguna que indicara su carácter festivo, comenzó su virtual vida lexicográfica, que llega a la última edición del diccionario usual de la Academia (DRAE 2014: s. v. cerdamen "Manojo de cerdas atadas y dispuestas para hacer brochas, cepillos, etc.").

\subsection{Pelamen}

El sustantivo pelamen se encuentra en el mismo pasaje del Estebanillo en el que ocurre la voz cerdamen:

[1646] Tomé un peyne, encaxéselo en aquella selva de clines [un bigote], arrimele el hierro y, levantándose una humareda horrenda, al son de un sonoro chirriar i de un olor de pie de puerco chamuscado, le hize chicharrón todo el pelamen. Alçó el grito diziéndome: - ¡Hijo de cien cabrones i de cien mil putas! ¿Piensas que soy San Lorenzo, que me quieres quemar vivo? [...] Sin dexar el hierro de la mano, i al tiempo que lo fuy a meter en la faltiquera, hallé pegado a él todo el bigote del tal hidalgo, que era tan descomunal que podía servir de cerdamen a un isopo i anegar con él una Iglesia al primer asperges. (La vida i hechos de Estevanillo González, hombre de buen humor, Amberes, 1646, pp. 9 y 10; CORDE).

Aunque en la primera mitad del siglo XVI se documenta en catalán el nombre pelam ("Conjunt de pèl d'una persona o animal; especialment, El conjunt de pèl arrabassat o tallat"; $D C V B, \mathrm{~s}$. v. ${ }^{56}$ ), en español parece que la palabra pelamen, más que un catalanismo, parece responder, como sucede con cerdamen, a un acto creativo del autor del Estebanillo, en el que se toman como modelo voces como las que hemos estudiado en este trabajo y que entonces, a mediados del siglo XVII, se empleaban sobre todo con el fonema nasal final. Nótese que ni cerdamen ni pelamen experimentaron el proceso paulatino de adaptación fonológica que sí tuvieron otras palabras analizadas ( $\S 3.1-3.6)$. Al igual que ocurre con cerdamen, las fuentes consultadas confirman que la voz pelamen, cuando fue utilizada en dicha novela, constituía una creación léxica ocasional (cfr. CORDE, CNDH, etc.). Esta misma conclusión fue a la que llegaron los primeros académicos, quienes registraron pelamen en el Diccionario de autoridades $(\mathrm{t} . \mathrm{V}, 1737)$ con la siguiente explicación en metalengua de signo: "Es voz del estilo jocoso". Apoyados en el único texto entonces disponible, el del Estebanillo, indicaron, además, que era "Lo mismo que Pelambre, en el sentido de Pelo"; y es que, en efecto, pelambre era el sustantivo que designaba el "conjunto de pelo en todo el cuerpo, $\mathrm{u}$ en algunas partes dél, y especialmente se toma por el arrancado o quitado, y singularmente por el que quitan los curtidores a las pieles" (Autoridades, ibíd.). Más adelante, también vendría a utilizarse, con el sentido que nos incumbe, pelambrera.

Ahora bien, hay que decir que pelamen, a diferencia de cerdamen, sí tomó cuerpo en el léxico español; ello sucedió a partir de mediados del siglo XIX, cuando aquel sustantivo comenzó a utilizarse en diversos textos, sobre todo - aunque no únicamente- en crónicas taurinas, donde se predicaba de los astados (97-100): 
(94) [1844] La desenvuelta cigarrera con los enaguas [sic] frisando en la pantorrilla, el delantal de coco, la mantilla de tira al desgaire pendiente de los hombros y el pelamen recogido en una ancha castaña sobre el cogote. (Los españoles pintados por sí mismos, Madrid, t. I, 1843, pp. 259-260; GB).

(95) [1852] Cuando María oyó de buenas a primeras el ofrescimiento de tan razonable cuantía por el su pelamen [...]. (Juan Eugenio Hartzenbusch, Doña Mariquita la Pelona, en El Tajo. Crónica Semanal de la Provincia de Toledo, 7 de septiembre de 1867, p. 143a; BVPH).

(96) [1869] El sombrero rasurado / encubridor del pelamen. (Antonio Hurtado, "El Facedor de un entuerto y el Desfacedor de agravios", en Fiesta literaria celebra en honor de Miguel de Cervantes Saavedra, Madrid, 1869, p. 76; BDH).

(97) [1877] Abría el calabozo núm. 1 para dar salida al cornúpeto número primero. Era este propiedad de Don Julián Bañuelos y salió andandito nada más, luciendo el pelamen retinto listón y la cuerna alta y apretada. (El Toreo, 25 de junio de 1877, p. $1 b$; HDBN).

(98) [1878] El segundo [toro] se llamaba Capirote, y lo era, teniendo el pelamen berrendo en colorado y la cuerna ancha. (La Iberia, 15 de mayo de 1878, p. 3e; HDBN).

(99) [1878] Salta al circo su hermano de vacada, rey y soberano, que trae por mal nombre Satinero y cuyas señas tal cual reza su cédula personal, achocolao de pelamen, ojo de perdiz, bien armado. (El Pueblo Español, 14 de octubre de 1878, p. 2d; BVPH)

(100) [1911] Podenco de nombre [un novillo], corniapretado de armamento y negro bragado de pelamen. (El Cantábrico, 2 de octubre de 1911, p. 2 b; BVPH).

Por lo tanto, aunque los nombres cerdamen y pelamen fueron en origen creaciones léxicas ocasionales, cada uno tuvo distinta suerte. Mientras que del primero solo quedó su registro lexicográfico, el segundo empezó a tener cierta vida más allá de los diccionarios a partir de la fecha indicada y su uso, que llega hasta nuestros días a pesar de que es ciertamente limitado, justifica que en la actualidad se incluya tanto en el diccionario usual de la Academia (DRAE 2014: "coloq. Conjunto de pelo"; cfr. Abc, La Vanguardia, El País; CREA, CV, DaviesE) como en DEA (2011), con el valor de 'pelaje, pelo de un animal', avalado con el siguiente texto de Lugo. España en paz (1964): "Más de un caballo de los de estos montes son de tamaño y traza que, por cebrados o rayados en su pelamen, con el de nuestra cuestión casan".

\section{CONSIDERACIONES FINALES}

En § 2 mostrábamos que algunas obras -entre las que se encuentran la Nueva gramática de la lengua española (2009) y el diccionario usual de la Academia (2014) - han considerado el sufijo amen como un elemento morfológico que, dentro de la derivación nominal, crea "sustantivos españoles derivados" que presentan valor colectivo; además, la Nueva gramática incluye el patrón "N-amen: vela > velamen" entre los "más productivos" (RAE/ASALE 2009: § 5.1b). Pues bien, ni 
estamos ante un patrón productivo ni se trata de un sufijo - y esto es lo que importa subrayarque haya dado lugar en español al grupo de palabras estudiadas. Tales sustantivos colectivos (a excepción de maderamen, cerdamen y pelamen, que presentan ciertas peculiaridades de las que hemos dado cuenta) son préstamos procedentes del catalán, del italiano y del portugués, lenguas en las que el sufijo patrimonial -am o -ame sí ha generado, y en algunos casos con profusión, nuevos nombres colectivos.

Descartada la sufijación como el procedimiento interno de creación de dichos nombres, se ha intentado establecer, basándonos principalmente en criterios cronológicos y morfológicos, cuál o cuáles han sido las lenguas que prestaron al español tales colectivos. Puede afirmarse que dos de las voces tratadas no ofrecen dudas: poleame $(n)$ procede del término portugués homólogo $(<$ port. poleame) y bestiame $(n)$ es un italianismo (< it. bestiame); ambos sustantivos se incorporaron al español en la primera mitad del siglo XVI. Sin embargo, no resulta tarea fácil confirmar la lengua originaria de otras voces. Aunque los sustantivos barrilamen, botamen y leñame(n) podrían ser catalanismos (< cat. barrilam, botam y llenyam), conviene no descartar la procedencia italiana $(<$ it. barilame, bottame y legname). Lo mismo sucede con velamen, documentado desde el siglo XV en catalán (velam), pero presente también en portugués desde el xvi (velame/vellame). Algo más claro resulta el caso de cordame(n), cuya etimología parece ser el italiano cordame, si bien no puede descartarse tajantemente la influencia del catalán cordam.

A estas alturas huelga decir que algunos de los sustantivos estudiados pertenecen al léxico de la marina. En relación con los catalanismos del español, Colón Doménech indica que, a pesar de la decadencia de la literatura catalana desde principios del siglo XVI hasta mediados del XIX, "el español seguirá recibiendo acervo léxico catalán durante todo el período áureo” (1967: 234); y concluye:

la influencia fue sensible a partir de comienzos del s. XV o tal vez ya a fines del s. XIV y se mantuvo lozana a lo largo del s. XVI. [...] También parece claro que en algunos compartimentos del léxico los elementos catalanes están mejor representados que en otros, por ejemplo en la terminología marítima y comercial. (Colón Doménech 1967: 237).

Verdonk (2004: 896), igualmente, pone de relieve la cuantiosa aportación de catalanismos náuticos al español durante el siglo XVI:

Una larga serie de voces catalanas había penetrado ya en castellano a lo largo de la Edad Media. Después de 1500 - y a pesar del estancamiento de la producción literaria catalana - este movimiento continúa, pero se detiene a finales del siglo XVI. El mayor número de préstamos se registra en el campo de la navegación ${ }^{57}$.

En el caso de los sustantivos barrilamen, botamen y leñame(n), cabe también la posibilidad de que fueran italianismos que llegaron al español por intermedio del catalán. A este respecto, Terlingen (1967: 283) recuerda que hay que tener en cuenta lo siguiente: 
Cataluña aparece temprano como una potencia marítima importante, que por su situación en el Mediterráneo ha mantenido relaciones íntimas con Italia y especialmente con las repúblicas comerciales. Como el catalán se hablaba antes del siglo XIV casi generalmente a lo largo de toda la costa mediterránea de la Península, esta lengua ha servido durante este período de intermedio de muchos términos náuticos de origen italiano. (Cfr. Terlingen 1967: 267 y Dworkin 2012: 139-140).

Terlingen lleva a cabo una relación de los numerosos italianismos que, por diversas vías, penetraron en el español; sin embargo, no recoge ninguno de los tres sustantivos mencionados, tampoco incluidos entre los términos náuticos pertenecientes a la "vida marítima" (Terlingen 1967: 283-286). Lo que es claro es que la mayoría de los italianismos del español pertenecen a los siglos XVI y XVII. Bestiame, precisamente, comienza a utilizarse en español a principios del XVI, fundamentalmente en textos que narran campañas bélicas desarrolladas en Europa, algunas de ellas en territorios de habla italiana.

En cuanto a la influencia del portugués en el español, Salvador Caja (1967: 244-250) recoge un buen puñado de lusismos relativos al léxico "del mar" (cfr. Vendonk 2004: 900), pero no menciona el portuguesismo poleame ${ }^{58}$. Documentar esta voz primero en español (c1519) y unos años después en portugués (1541) no es óbice, desde luego, para asegurar que esta fue la lengua transmisora; ello es lo que parecen indicar los primeros testimonios que hemos aducido en este trabajo, en los que se habla de algunos pertrechos marítimos que requirió el navegante portugués Fernando de Magallanes durante las expediciones realizadas bajo la corona de Carlos v.

El estudio monográfico de las voces consideradas, basado en la abundantísima documentación que ofrecen los corpus y las distintas fuentes manejadas, nos ha permitido trazar la cronología de los nombres en -ame(n) y comprobar, como muestran muchos de los textos citados, que la mayoría de los sustantivos tratados son préstamos que el español adquirió en diversas situaciones de contacto de lenguas, como las que se produjeron en los intercambios comerciales por mar, en la expansión ultramarina y en las diversas campañas bélicas emprendidas durante el reinado de los Austrias mayores, es decir, Carlos V y Felipe II. Casi todos los préstamos considerados proceden del siglo XVI, sobre todo de su primera mitad (poleame(n)-c1519; botamen-1524; leñame(n)-15331534; bestiame(n)-1533-1534; velame(n)-1565), mientras que cordame(n)-1613 y barrilamen1614 se emplearon ocasionalmente en el XVII. Por otro lado, hemos constatado que en general los sustantivos estudiados no superaron el siglo XVII; constituyen una excepción, sin embargo, los colectivos velamen y maderamen, que han llegado a nuestros días. No solo debe considerarse excepcional maderame(n) por su cronología, sino por el hecho de que no es propiamente un préstamo. A nuestro juicio, se trata de una creación inducida tanto por el modelo del catalán fustam como por el sustantivo leñame(n); sería, por tanto, una formación que se encontraría entre el léxico adquirido (préstamos) y el léxico multiplicado (en este caso, derivación) (cfr. Álvarez de Miranda 2009: 146-147). Tampoco pertenecen al grupo de los colectivos tomados de otras lenguas romances las voces cerdamen y pelamen. No cabe duda de que estos sustantivos tienen una menor relevancia al tratarse de ocasionalismos en el periodo considerado ${ }^{59}$, pero, aun así, también poseen cierto interés en tanto en cuanto ponen de manifiesto el auge de los términos en -amen que circulaban a mediados del siglo XVII y que sirvieron de modelo para su formación. Téngase en cuenta que, de acuerdo con los textos citados en este trabajo, la terminación -ame se asocia al siglo XVI (s. XVI: 62,1\%; s. XVII: 37,9\%), mientras que la terminación -amen predomina claramente en sustantivos del XVII (s. XVI: 16,4\%; s. XVII: 83,6\%) ${ }^{60}$. Esta distribución cronológica también explica en cierto modo que los escasos testimonios que conocemos del sustantivo barrillamen — todos del 
s. XVII - presenten esta variante y no *barrilame, forma esta última que habría sido esperable si hubiera comenzado a circular en español en la centuria anterior.

Finalmente, pueden hacerse tres consideraciones generales a partir del estudio exhaustivo de los sustantivos que nos han ocupado. Tal y como se indicaba en $\S 1$, para la obtención de los textos citados nos hemos servido, entre otros recursos, de CORDE. No será necesario encarecer la aportación que este corpus académico ha supuesto para el estudio del español, y especialmente para los trabajos léxicos de corte diacrónico. Ahora bien, en muchas ocasiones la utilización de este corpus resulta ostensiblemente insuficiente. Para el periodo 1500-1700 apenas ofrece textos que contengan las voces en -ame(n) estudiadas. No recoge ningún texto de barrilame(n) y botame(n), aunque ello es esperable, y comprensible, dada la escasa documentación disponible para estas voces. De bestiame(n) se recuperan 9 casos en 3 documentos; de leñame, 11 casos en 6 documentos; de maderame, 6 casos en 3 documentos; de poleame, 2 casos en 2 documentos; de cordamen, 1 caso. En cambio, la voz velamen 'conjunto de velas' parece que está mejor representada: 13 casos en otros tantos documentos ${ }^{61}$. De la consulta del CORDE se desprende la conclusión de que resulta totalmente necesario acudir a otros corpus y a otras fuentes si se desea tener ciertas garantías a la hora de trazar la vida de una palabra. En efecto, la trayectoria de cada uno de los sustantivos en -ame(n) estudiados no habría sido posible sin la concurrencia de otras herramientas filológicas que la informática e internet ponen a nuestro alcance en la actualidad. Entre otras, nos estamos refiriendo al opimo Fichero general de la Real Academia Española y a otros muchos recursos de acceso en línea que en los últimos años están brindando un servicio extraordinario a los estudios filológicos, tales como bibliotecas y hemerotecas digitales, otros corpus académicos y extraacadémicos, Google Books, Internet Archive, etc.

La segunda consideración general que querríamos hacer se encamina en derechura al registro lexicográfico que han tenido las voces en -ame(n) estudiadas. Una vez que ha quedado establecida su cronología, que como sabemos se limita en la mayoría de los casos a los siglos XVI y XVII, estamos en condiciones de valorar su codificación lexicográfica. Sorprende observar que sigan figurando en el diccionario usual de la Academia barrilamen y botamen, que apenas tuvieron uso en español; si se desea mantener estas voces, al menos deberían llevar una marca relativa a la vigencia histórica que indicara que dejaron de estar en circulación hace varios siglos (¿quizá la marca “desus."?). En realidad, casi todos los sustantivos estudiados tendrían que llevar dicha marca, pues no superaron el Seiscientos ${ }^{62}$. Por otro lado, el artículo bestiame se suprimió del diccionario académico en la edición de 2011; sin embargo, esta voz debería tener el mismo derecho de permanecer en dicho repertorio: de hecho, en realidad son más los textos que conservamos de bestiame $(n)$ que los disponibles para barrilamen y botamen. Otro aspecto que podría mejorarse aunque no merece la pena extenderse en ello - atañe a la lematización: ¿convendría recoger las formas en -ame o en -amen en los sustantivos que presentan variación? En algunos casos el diccionario usual incluye (o incluyó) únicamente la primera forma: bestiame y poleame; ahora bien, sabemos que las variantes en -ame se asocian al siglo XVI, mientras que las variantes en -amen se difundieron en la centuria siguiente. Silenciar en el diccionario las formas más evolucionadas no parece lo más oportuno y, por otro lado, prescindir de las formas en -ame no respondería a la realidad histórica de tales voces. Quizá lo más conveniente sería recoger ambas formas, y que las variantes en -ame remitieran a los sustantivos correspondientes en -amen. En cuanto a las marcas técnicas relativas a determinadas actividades del hombre, botamen (2. acep. 'pipería') y poleame llevan la marca "Mar[ina]", pero quizá no deberían ser las únicas que tendrían que llevarla: serían buenos candidatos los nombres barrilamen y velamen, aunque esta última ya ha perdido, desde 
luego, su carácter especializado. El nombre leñame, en fin, plantea otro tipo de problema, y es que, según nuestras indagaciones, la segunda acepción que ahora se recoge en el diccionario usual nunca existió.

Por último, parece oportuno decir algo sobre los derivados nominales en -amen, sin valor colectivo, que la Nueva gramática caracteriza como "creaciones recientes, unas veces humorísticas y otras vulgares" (RAE/ASALE 2009: $§ 6.13 u$; cfr. nota 13 del presente artículo). Dado el marco cronológico de este estudio y teniendo en cuenta las voces aquí consideradas (todas ellas colectivas), es evidente que aquellos debían quedar fuera de nuestro alcance, puesto que, sin duda, son harina de otro costal. Ahora bien, existe entre unas y otras un vínculo que no solo se basa en la morfología. El diccionario usual de la Academia recoge, entre otras, voces como caderamen o muslamen, derivados surgidos a partir de un patrón morfológico que posee - este sí- cierta actividad en el español contemporáneo; sin embargo, dicho diccionario no recoge este procedimiento en el artículo dedicado al morfema -amen, que, como sabemos, solo incluye los dos usos que presentábamos en $\S 2$, uno relativo a los sustantivos tomados del latín, como dictamen, y otro atinente a los mal descritos "sustantivos españoles derivados" con valor colectivo, como velamen. Es manifiesto que tal artículo es mejorable, no solo en los aspectos ya señalados, sino en relación con la necesidad de incluir el patrón que únicamente es "productivo" en el español de nuestros días. Explorar la productividad de este sufijo -amen y el desenvolvimiento de las voces a que ha dado lugar habrá de ser el objeto de estudio en un trabajo ulterior.

\section{Corpus y otras fuentes de información}

$A b c=$ Hemeroteca del $A b c$ [en línea] <http://hemeroteca.abc.es>. [30/11/2019]

Archive = Internet Archive [en línea] <https://archive.org>. [30/11/2019]

$\mathrm{BDH}=$ Biblioteca Nacional de España: Biblioteca Digital Hispánica [en línea] <http://www.bne.es/es/Catalogos/BibliotecaDigitalHispanica/Inicio/>. [30/11/2019]

BDMM = Ayuntamiento de Madrid: Biblioteca Digital memoriademadrid [en línea] <http://www.memoriademadrid.es>. [30/11/2019]

$\mathrm{BVPB}=$ Ministerio de Cultura y Deporte, Biblioteca Virtual del Patrimonio Bibliográfico [en línea] <https://bvpb.mcu.es>. [30/11/2019]

$\mathrm{BVPH}=$ Ministerio de Cultura $\mathrm{y}$ Deporte: Biblioteca Virtual de Prensa Histórica [en línea] <http://prensahistorica.mcu.es/es/consulta/busqueda.cmd>. [30/11/2019]

CHARTA = Corpus Hispánico y Americano en la Red: Textos Antiguos [en línea] < http://www.corpuscharta.es $>$. [30/11/2019]

CICA = J. Torruella (dir.), junto con M. Pérez Saldanya y J. Martines: Corpus Informatitzat del Català Antic [en línea] <http://cica.cat/index.php>. [30/11/2019]

CIPM = Centro de Linguística da Universidade NOVA de Lisboa: Corpus Informatizado do Português Medieval [en línea] <https://cipm.fcsh.unl.pt>. [30/11/2019]

$\mathrm{CNDH}=$ Instituto de Investigación Rafael Lapesa de la Real Academia Española: Corpus del Nuevo diccionario histórico [en línea] < http://web.frl.es/CNDHE>. [30/11/2019]

CODEA = Grupo de Investigación Textos para la Historia del Español: CODEA+ 2015. Corpus de Documentos Españoles Anteriores a 1800 [en línea] <http://corpuscodea.es>. [30/11/2019] 
CORDE = Real Academia Española: Banco de datos (CORDE) [en línea] Corpus diacrónico del español, $<$ http://www.rae.es $>$. [30/11/2019]

CORDIAM = Academia Mexicana de la Lengua: Corpus Diacrónico y Diatópico del Español de América [en línea] $<$ www.cordiam.org>. [30/11/2019]

CORLEXIN = J. R. Morala Rodríguez (dir): Corpus Léxico de Inventarios [en línea] $<$ http://web.frl.es/CORLEXIN.html>. [30/11/2019]

CORPES = Real Academia Española: Banco de datos (CORPES) [en línea]. Corpus del español del siglo XXI, <http://www.rae.es>. [30/11/2019]

CREA = Real Academia Española: Banco de datos (CREA) [en línea]. Corpus de referencia del español actual, <http://www.rae.es>. [30/11/2019]

CTILC = Institut d'Estudis Catalans: Corpus Textual Informatitzat de la Llengua Catalana [en línea] $<$ https://ctlc.iec.cat>. [30/11/2019]

$\mathrm{CV}=$ Biblioteca Virtual Miguel de Cervantes: Cervantes Virtual [en línea] <www.cervantesvirtual.com>. [30/11/2019]

DaviesE = M. Davies: Corpus de Español: Web/Dialectos [en línea] <https://www.corpusdelespanol.org/web-dial/>. [30/11/2019]

DaviesP = M. Davies: Corpus do Portuguese: Genre/Historical [en línea] < $\underline{\text { www.corpusdo- }}$ portugues.org./X.asp>. [30/11/2019]

Fich. Ac. = Real Academia Española: Fichero general [en línea] <http://www.rae.es $>$. [30/11/2019]

Galiciana = Secretaría Xeral de Cultura de la Xunta de Galicia: Galiciana. Biblioteca Dixital de Galicia [en línea] <http://biblioteca.galiciana.gal/gl/inicio/inicio.do>. [30/11/2019]

GB = Google: Google Books [en línea] <https://books.google.es $>$. [30/11/2019]

HDBN = Biblioteca Nacional de España: Hemeroteca Digital [en línea] <http://hemerotecadigital.bne.es/index.vm>. [30/11/2019]

HRAG = Real Academia Galega, Hemeroteca Virtual [en línea] <https://academia.gal/hemeroteca-virtual $>$. [30/11/2019]

El País = Buscador de El País [en línea] <https://elpais.com/buscador/>. [30/11/2019]

TILG = Instituto $\mathrm{da}$ Lingua Galega: Tesouro Informatizado da Lingua Galega [en línea] $<$ http://ilg.usc.es/TILG/>. [30/11/2019]

La Vanguardia = Hemeroteca de La Vanguardia [en línea] <https://www.lavanguardia.com/hemeroteca> . [30/11/2019]

\section{Bibliografía}

ALEMANy Bolufer, J. (1920): Tratado de la formación de palabras en la lengua castellana: la derivación y la composición. Estudio de los sufijos y prefijos empleados en una y otra. Madrid.

ALmela PÉREZ, R. (1999): Procedimientos de formación de palabras en español. Barcelona: Ariel.

Alvar, M.; PotTier, B. (1983): Morfología histórica del español. Madrid: Gredos.

Álvarez Martínez, M. a Á. (1997): “El español y el portugués: aspectos léxicos”, Cuadernos Hispanoamericanos 570, pp. 15-28. 
Álvarez De Miranda, P. (2009): “Neología y pérdida léxica”, in E. de Miguel (ed.): Panorama de la lexicología. Barcelona: Ariel, pp. 133-158.

AMorim, J. P. (1841): Diccionario de marinha. Lisboa.

BADIA MARGARIT, A. M. (1962): Gramática catalana. Madrid: Gredos, 2 vols.

BÁEz Montero, I. C. (2006): "Los lusismos en los diccionarios informatizados de la Academia", in J. J. de Bustos Tovar y J. L. Girón Alconchel (eds.): Actas del VI Congreso Internacional de Historia de la Lengua Española. Madrid: Arco/Libros, vol. II, pp. 1269-1283.

BARbosa, O. (1992): Diccionário de coletivos da língua portuguesa. Brasília: Thesaurus.

BLUTEAU, R. (1712-1728): Vocabulário português e latino. Coimbra/Lisboa.

CASAS, C. de las (1570): Vocabulario de las dos lenguas toscana y castellana. Sevilla.

Colón Doménech, G. (1967): “Catalanismos”, in M. Alvar et al. (dirs.): Enciclopedia Lingüística Hispánica. Madrid: CSIC, vol. II [Elementos constitutivos. Fuentes], pp. 193-238.

CoOPer, F. T. (1895): Word Formation in the Roman Sermo Plebeius. An Historical Study of the Development of Vocabulary in Vulgar and Late Latin, with Special Reference to the Romance Languages, tesis doctoral. Nueva York.

Corbella, D.; FAJARdo, A. (eds.) (2017): Español y portugués en contacto. Préstamos léxicos e interferencias. Berlín/Boston: De Gruyter. https://doi.org/10.1515/9783110552027.

Covarrubias OrozCo, S. de (1611): Tesoro de la lengua castellana o española. Madrid.

Cunha, A. G. da (2010): Dicionário etimológico da língua portuguesa, 4. a edición revisada y actualizada. Río de Janeiro: Lexikon.

[DCECH =] COROMINAS, J. (1980-1991): Diccionario crítico etimológico castellano e hispánico, con la colaboración de J. A. Pascual. Madrid: Gredos, 6 vols.

[DCVB $=$ ] Alcover, A. M. $;$; MolL, F. de B. (1930-1962): Diccionari català-valencià-balear. Palma de Mallorca: Moll, 10 vols.

[DdD =] Instituto da Lingua Galega: Dicionario de dicionarios [en línea] <http://sli.uvigo.es/DdD>. [30/11/2019]

[DDLC=] Institut D'Estudis CATAlAnS: Diccionari descriptiu de la llengua catalana [en línea]

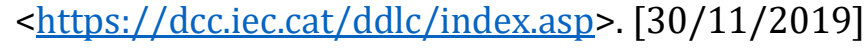

[DEA =] SECO, M.; ANDRÉS, O.; RAMOS, G. (2011): Diccionario del español actual, 2. a edición actualizada. Madrid: Aguilar Lexicografía, 2 vols.

[DECat =] CoRominaS, J. (1991-1995): Diccionari etimològic i complementari de la llengua catalana, 6. ed. Barcelona: Curial Edicions Catalanes/Caixa de Pensions "La Caixa”, 9 vols. [Con la colaboración de J. Gulsoy y M. Cahner].

[DELI =] CorTelazzo, M.; Zolli, P. (1999): Il nuovo etimologico. Dizionario Etimologico della Lingua Italiana, 2. ${ }^{\text {a }}$ ed., Bolonia: Zanichelli.

[DHist. =] REAL ACADEMIA EsPaÑola (1933-1936): Diccionario histórico de la lengua española. Madrid, 2 ts. [T. I: A, t. II: B-cevilla].

[Diccionari Aguiló =] AGuiló I Fuster, M. (1915-1934): Diccionari Aguiló. Materials lexicogràfics aplegat per 一, revisados y publicados bajo el cuidado de P. Fabra y M. de Montoliu. Barcelona: Institut d'Estudis Catalans, 8 ts. 
[Diccionari Balari =] BALARI Y JovANY, J. (1927-1928): Diccionari Balari. Inventario lexicográfico de la lengua catalana, compilado por el Dr. D. - y dispuesto para su publicación por el Dr. D. M. de Montoliu. Barcelona: s. a. [pero 1927-1928; contiene las letras A-G].

[Diccionario de autoridades 1726-1739 =] V. REAL ACADEMIA ESPAÑOLA (1726-1739).

[Diccionario de autoridades 1770 =] V. REAL ACADEMIA ESPAÑOLA (1770).

Diccionario marítimo español, que, además de las definiciones de las voces con sus equivalentes en francés, inglés e italiano, contiene tres vocabularios de estos idiomas con las correspondencias castellanas (1831). Madrid.

[DICIweb =] Universidade de Aveiro/Centro de Linguística da Universidade de Lisboa: Corpus Lexicográfico do Português [en línea] <http://clp.dlc.ua.pt/Inicio.aspx>. [30/11/2019]

[DICTER 2 =] Diccionario de la ciencia y de la técnica del Renacimiento, dirigido por M. a Jesús Mancho Duque, Universidad de Salamanca [en línea] <http://dicter.usal.es>. [30/11/2019]

[DRAE 1780 =] REAL ACADEMIA ESPAÑOla (1780): Diccionario de la lengua castellana, reducido a un tomo para su más fácil uso, [1. $\stackrel{\mathrm{a}}{\mathrm{ed}}$.]. Madrid.

[DRAE 1803 =] REAL ACADEMIA ESPAÑOla (1803): Diccionario de la lengua castellana, reducido a un tomo para su más fácil uso, 4. ㄹ ed. Madrid.

[DRAE 1817 =] REAL ACADEMIa ESPAÑOLA (1817): Diccionario de la lengua castellana, 5. a ed. Madrid.

[DRAE 1884 =] REAL ACADEMIa ESPAÑOla (1884): Diccionario de la lengua castellana, 12. a ed. Madrid.

[DRAE 1914 =] REAL ACADEMIA ESPañola (1914): Diccionario de la lengua castellana, 14. a ed. Madrid.

[DRAE 1936-1939=] REAl ACADEMIA ESPAÑola (1936-1939): Diccionario de la lengua española, 16. ${ }^{\text {a }}$ ed. Madrid: Espasa-Calpe.

[DRAE 1970 =] REAL ACADEMIA ESPAÑOla (1970): Diccionario de la lengua española, 19. a ed. Madrid: EspasaCalpe.

[DRAE 2001 =] REAL ACADEMIA EsPAÑOla (2001): Diccionario de la lengua española, 22.. ed. Madrid: EspasaCalpe.

[DRAE 2014 =] REAl ACADEMIa ESPAÑola (2014): Diccionario de la lengua española, 23. a ed. Madrid: Espasa.

Dworkin, S. N. (2012): A History of the Spanish Lexicon. A Linguistic Perspective. Nueva York: Oxford University Press. https://doi.org/10.1093/acprof:oso/9780199541140.001.0001.

Dworkin, S. N. (2016): “Historia del español: léxico”, in J. Gutiérrez-Rexach (ed.): Enciclopedia de Lingüística Hispánica. Londres/Nueva York: Routledge, vol. 2, pp. 536-546. https://doi.org/10.4324/9781315713441-122.

ESCRIG Y MARTíNEZ, J. (1887): Diccionario valenciano-castellano, 3. ${ }^{\text {a }}$ ed. Valencia.

FABRA, P. (1912): Gramática de la lengua catalana. Barcelona: Tipografía L’Avenç.

[Faraudo=] FARAUDo DE SAINT-GERMAIN, Ll.: Vocabulari de la llengua catalana medieval [en línea] <http://www.iec.cat/faraudo/>. [30/11/2019]

FARIA, E. de (1850-1853): Novo diccionario da lingua portugueza, 2. ${ }^{\mathrm{a}}$ ed. Lisboa, 4 vols.

FERNÁNDEZ RAMíREZ, S. (1986): La derivación nominal, ordenado, anotado y dispuesto para la imprenta por I. Bosque. Madrid (Anejos del BRAE, n. 느).

Forteza y CORTÉs, T. (1915): Gramática de la lengua catalana. [Palma de Mallorca]: Escuela Tipográfica Provincial. [Con un prólogo de A. M. a Alcover]. 
FRISONI, G. (1917): Dizionario moderno italiano-spagnuolo e spagnuolo-italiano. Milán: Ulrico Hoepli.

GARCÍA DE DiEGo, V. (1914): Elementos de gramática histórica castellana. Burgos.

[GDLI=] BAtTaglia, S. (1961-2002): Grande dizionario della lingua italiana. Turín: Unione TipograficoEditrice Torinese, 21 vols. [Consultable en línea: <http://www.gdli.it>]. [30/11/2019]

GONZÁLEZ OlLÉ, F. (1975-1976): "Contribución al estudio de los italianismos en español en el siglo XVI", Filología Moderna XVI, pp. 195-206.

Gran diccionario de la lengua española (2012): 4.a ed. Barcelona: Larousse. [J. Induráin Pons (dir.) y S. Acebo García (coord.)].

HANSSEN, F. (1913): Gramática histórica de la lengua castellana. Halle: Max Niemeyer.

JAL, A. (1848): Glossaire nautique. Répertoire polyglotte de termes de marine anciens et modernes. París, 2 vols.

LANG, M. F. (2002): Formación de palabras en español. Morfología derivativa productiva en el léxico moderno, adaptación y traducción de A. Miranda Poza, 3. - ed. Madrid: Cátedra.

MACHADO, J. P. (2003): Dicionário etimológico da língua portuguesa, com a mais antiga documentação escrita e conhecida de muitos dos vocábulos estudados, 8. ${ }^{\text {a }}$ ed. Lisboa: Livros Horizonte, 5 vols.

MEYER-LÜBKE, W. (1895): Grammaire des langues romanes. París: Welter [Tome deuxième: morphologie].

MEYER-LÜBKE, W. (1921): Historische Grammatik der französischen Sprache, t. II, Wortbildungslehre. Heidelberg: Carl Winter.

MEYER-LÜBKE, W. (1925): Das Katalanische. Seine Stellung zum Spanischen und Provenzalischen, sprachwissenschaftlich und historisch dargestellt. Heidelberg: Welter, Carl Winter.

MolL, F. de B. (2006[1952]): Gramàtica històrica catalana, edición corregida y anotada por J. Martí Mestre con la colaboración de J. Jiménez. Valencia: Universitat de València.

Monteil, P. (1992): Elementos de fonética y morfología del latín, traducción de Concepción Fernández Martínez. Sevilla: Universidad de Sevilla. https://doi.org/10.12795/9788447221011.

NEBRIJA, E. A. (1495): Dictionarium ex hispaniensi in latinum sermonem. Salamanca, s. a. [Conocido como Vocabulario español-latino].

NogueIRA, R. de Sá (1945 y 1948): “Crítica etimológica”, Boletim de Filologia 8 (1945), pp. 1-56, 185-236, 357-364; 9 (1948), pp. 197-228 y 321-339. [Una parte sustantiva del estudio se dedica a las "Palavras castelhanas de origem portuguesa"].

[NTLle $=$ ] Real ACAdemia EsPañola (2001): Nuevo Tesoro Lexicográfico de la Lengua Española. Madrid. Edición en 2 DVD. [También consultable en línea] <https://www.rae.es>. [30/11/2019]

PANTERA, P. (1614): “Vocabolario nautico”, in L'armata navale del capitán Pantero Pantera. Roma.

PerRot, J. (1961): Les dérivés latins en -men et -mentum. París.

PHARIES, D. (2002): Diccionario etimológico de los sufijos españoles y de otros elementos finales. Madrid: Gredos.

Prieto García-SECO, D. (2019): «José Alemany y Bolufer: trayectoria filológica e hitos fundamentales», in J. L. Aparici Gayon (ed. y coord.): XIII Jornades d'Estudis de Cullera. Cullera, 24, 25 i 26 de novembre de 2017. Cullera: Ayuntamiento de Cullera, pp. 47-95.

[RAE/ASALE 2009 =] REAL ACADEMIA ESPAÑOLA/ASOCIACIÓN DE ACADEMIAS DE LA LENGUA ESPAÑOLA (2009): Nueva gramática de la lengua española. Madrid: Espasa. 
RAINER, F. (1993): Spanische Wortbildungslehre. Tubinga: Niemeyer. https://doi.org/10.1515/9783110956054.

REAL ACADEMIA ESPAÑola (1726-1739): Diccionario de la lengua castellana [...]. Madrid, 6 vols.

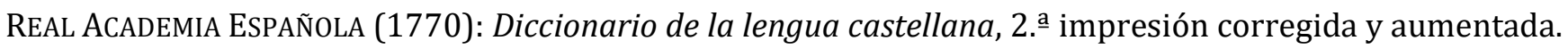
Madrid, vol. I [y único; letras A y B].

REAL ACADEMIa ESPAÑOLA (1920): Gramática de la lengua castellana. Madrid.

Salvador Caja, G. (1967): "Lusismos”, in M. Alvar et al. (dirs.): Enciclopedia Lingüística Hispánica. Madrid: CSIC, vol. II [Elementos constitutivos. Fuentes], pp. 239-261.

SAntiago Lacuesta, R.; Bustos Gisbert, E. (1999): “La derivación nominal”, in I. Bosque y V. Demonte (dirs.): Gramática descriptiva de la lengua española. Madrid: Espasa Calpe, vol. 3, pp. 4505-4594.

Silva, A. de M. (1831): Diccionario da lingua portugueza, 4. ${ }^{\text {a }}$ ed. "posta em ordem, correcta e enriquecida de grande numero de artigos novos e dos synonymos por Theotonio José de Oliveira Velho". Lisboa, 2 vols.

TERLINGEN, J. (1967): “Italianismos”, in M. Alvar et al. (dirs.): Enciclopedia Lingüística Hispánica. Madrid: CSIC, vol. II [Elementos constitutivos. Fuentes], pp. 263-305.

[TLIO =] SQUILlacioti, P. (dir.) (1997-2019): Tesoro della Lingua Italiana delle Origini, fundado por P. G. Beltrami [en línea] <http://tlio.ovi.cnr.it/TLIO/>. [30/11/2019]

Tomaseo, N.; Bellini, B. (1865-1879): Dizionario della lingua italiana. Turín, 8 vols. [en línea] <http://www.tommaseobellini.it/\#/>. [30/11/2019]

[VAC=] AcCademia della Crusca (1612): Vocabolario degli Accademici della Crusca. Venezia [en línea] <http://vocabolario.sns.it/html/>. [30/11/2019]

[VAC5 =] ACCAdEMia DElla CRuSCA: Lessicografia della Crusca in Rete [acceso a las cinco ediciones del

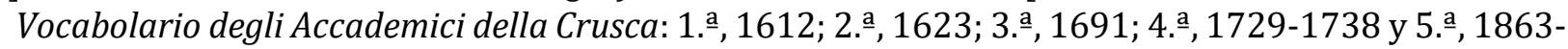
1923] [en línea] <http://www.lessicografia.it/index.jsp>. [30/11/2019]

VAREla ORTEGa, S. (2005): Morfología léxica: la formación de palabras, con la colaboración de S. Fabregat Barrios. Madrid: Gredos.

VERDONK, R. (2004): “Cambios en el léxico del español durante la época de los Austrias”, in R. Cano (coord.): Historia de la lengua española. Barcelona: Ariel, pp. 895-916.

VIEIRA, D. (1871-1874): Grande diccionario portuguez ou Thesouro da lingua portugueza. Oporto, 5 vols.

\section{Notas}

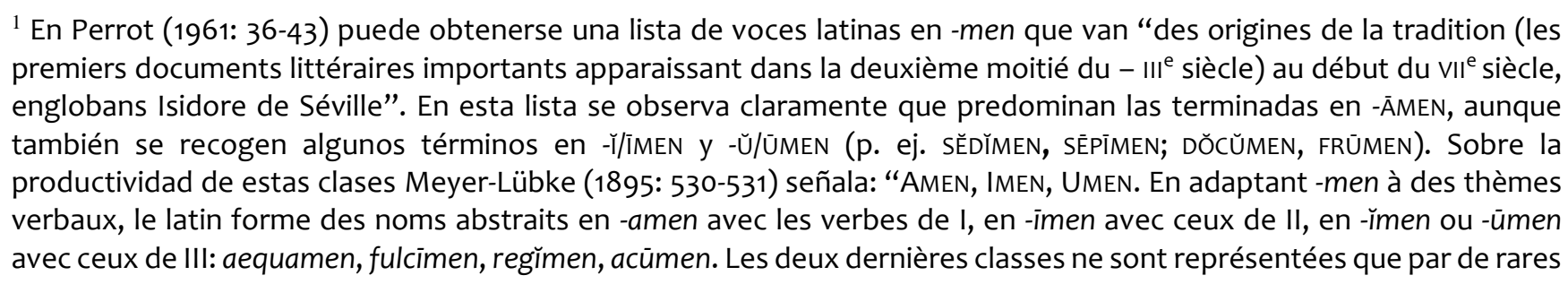


exemples: cf. specimen, sedimen, tegimen, genimen et documen; volūmen, stat[ümen], puis sans verbe à la base leg[ümen], vel[ümen] (la laine tondeu), alb[ümen] (blanc d'œuf) et ferr[ümen] (gomme). En roman, nous n'avons guère à nous occuper de -imen. Regìmen seul a persisté dans la langue écrite de la Gaule [... ]. Les autres mots en -immen ne sont pas représentés" (cfr. Cooper 1895: 84-88; Monteil 1992: 207). Al ocuparnos en el presente trabajo de los nombres españoles en -ame(n), prestaremos atención especialmente a los sustantivos latinos en -ĀMEN.

2 Siguiendo seguramente a Meyer-Lübke, en su Gramàtica històrica catalana Moll (2006[1952]: 242) indica: "En Ilatí formava originàriament noms abstractes derivats de verbs, però també va passar a tenir valor collectiu quan s'aplicava a radicals nominals".

${ }^{3}$ Perrot (1961: 205) afirma: "Les données romanes éclairent certains variétés de collectifs qui se présentent déjà en latin".

${ }^{4}$ Es variante del citado maçame.

${ }^{5}$ Badia Margarit (1962: II, 319-320) añade que en algunos casos el sufijo -am, "referido a personas, no deja de acumular un ligero matiz despectivo: donam 'mujerío' (< dona 'mujer'), mossam 'conjunto de mozas' (< mossa), lladregam 'cuadrilla de ladrones' (< lladre 'ladrón')”.

${ }^{6}$ Dejamos aparte el francés, lengua que, en relación con las palabras que nos interesan, no parece haber influido en el español, además de que tal sufijo no es muy productivo en ella. Sobre la formación autóctona del tipo de colectivos que nos atañen, Meyer-Lübke (1895: 532) señala: "le FRANÇAIS nous offre moins d'exemples, où l'orthographe moderne remplace souvent -ain par -in: funin, merrain, ridain, en a.-franç. arsain (embrasement), fer[ain] (farouche), lor[ain] (courroies), pel[ain] (peaux), etc., puis le dérivés à thème verbal alevin, counvain, levain, lien, l'a[ncien]-franç̧ais] naissain, ensuite le poitev[in] frešẽ (puanteur), le saintong[geais] fortẽ (mets fort épicés), le norm[and] süršẽ (souris)" (cfr. Meyer-Lübke 1921: § 79).

${ }^{7}$ La terminación latina -men también produjo, naturalmente, nombres en -imbre o -umbre (< lat. -IMEN y -UMEN): curtimbre, escurrimbre, urdimbre; herrumbre, pesadumbre, salumbre, techumbre, undumbre (ejemplos tomados de Meyer-Lübke 1895: 532 y 535).

${ }^{8}$ Alvar y Pottier (1983) no se ocupan de los sufijos -mbre ni -men; tan solo los mencionan a propósito del género de los sustantivos en virtud de su terminación: "los que acaban en -amen, -umen (certamen, resumen), que remontan a neutros latinos [...]. Por último, vacilan en cuanto a su género gramatical los en -mbre (el enjambre, el nombre, el alambre, pero la legumbre, la lumbre), que remontaban a un neutro latino -mine" (43-44).

9 En la misma línea Meyer-Lübke (1895: 532): "L'espagnol à son tour n'en possède pas beaucoup plus: osambre (ossements), pel[ambre] (poils), raig[ambre] (racines), puis hor[ambre] (foramen, trou) et vel[ambre] (ordination)". Unos años más tarde, Meyer-Lübke, en una obra dedicada al catalán (Das Katalanische), ponía de manifiesto que, mientras que en español son escasas las formaciones procedentes del -amen latino, en provenzal y, sobre todo, en catalán son frecuentes: “Amen ist span. selten, katal. und prov. häufig”, y seguidamente cita los nombres españoles horambre, osambre y raigambre; los catalanes cordam, cuyram, donam, fustam, llenyam, postam, ossam, pelam, arrelam, rocam, rodam y rossam; y los provenzales cordam, lenham, postam, pelam, roucan y roudan (1925: 92).

${ }^{10}$ Queda fuera de este estudio el nombre vigamen 'conjunto de vigas', que, pese a poseer la misma morfología e idéntico valor colectivo, penetra en español después del periodo aquí considerado. Su uso comienza en el siglo XIX: "Suelos entarimados, y en parte solo con el vigamen" (Diario de Madrid, 29 de agosto de 1844, p. 1C; HDBN); "Hizo quitar las azoteas de la catedral, cubriéndola de vigamen de mucha resistencia” (José A. Márquez de Prado, Recuerdos de África. Historia de la plaza de Ceuta..., Madrid, 1859, p. 217; Archive); "Todavía se presenta a nuestros ojos aquel espectáculo que llenaba de pavor; el horroroso chirrido del vigamen, el estrépito producido por las techumbres al desplomarse" (Vicente Guillot Almonacid, Memoria leída el 20 de octubre de 1878 en el Ateneo-Casino Obrero de Valencia, Valencia, 1878, p. 4; BVPH). No obstante, no parece que esta voz haya tenido mucho éxito en español; sin duda, ha impedido su afianzamiento la existencia del sustantivo sinónimo viguería, documentado desde principios el siglo XVII. Covarrubias afirmaba en su Tesoro de la lengua castellana o española (1611) que la viga es "vna pieça de madero gruessa; destas ponemos en los edificios, y sobre ellas se suelen cargas los quartones, para formar el techo en los palacios y casas principales. Todo el dicho techo es la viguería y artesones" (s. v. viga). Cfr. bigam en DCVB y CICA.

${ }^{11}$ A este respecto, RAE/ASALE (2009: § 6.13u) señala, con acierto, que "El sufijo latino -ämen no constituye un segmento morfológico en el análisis sincrónico de algunos cultismos (certamen, dictamen, examen, gravamen)". 
${ }^{12}$ Es muy probable que el artículo -amen, presente en el diccionario usual desde 1992, esté inspirado en el Tratado de la formación de palabras en la lengua castellana: la derivación y la composición. Estudio de los sufijos y prefijos empleados en una y otra (1920), del académico José Alemany y Bolufer. La influencia de este Tratado, que había sido un encargo de la Academia, se notó, en primer lugar, en la Gramática de la lengua castellana de 1920, donde se incluyó un nuevo capítulo llamado "De la formación de palabras. La derivación, la composición y la parasíntesis" (RAE 1920: 142-165; cfr. Prieto García-Seco 2019: 64). En la derivación nominal de este capítulo hay una relación de "sufijos tónicos usados en la formación de nombres y de adjetivos" y, entre ellos, figura -amen: "En substantivos latinos, como certamen, y en algunos derivados castellanos con significación colectiva: botamen y pelamen, de bote y pelo" (RAE 1920: 146).

${ }^{13}$ En otros tratados morfológicos o bien se prescinde de -amen (Fernández Ramírez 1986; Santiago Lacuesta y Bustos Gisbert 1999; Lang 2002; Varela Ortega 2005), o bien se recoge aquel sufijo (Almela Pérez 1999: 108), pero, sobre todo, en relación con palabras como juergamen, ladrillamen, muslamen, nalgamen, papelamen, polvamen, es decir, voces distintas de las que aquí estudiamos, formadas mucho después de los siglos considerados en este trabajo. Cfr. Rainer (1993: 403), quien afirma que los derivados de nombres que designan partes del cuerpo, algunos de ellos vulgares, gozan de gran popularidad: "Besonders beliebt sind Ableitungen von Körperteilen, speziell solchen, die paarweise auftreten: caderamen, cuernamen, nalgamen, patamen, pechamen, piernamen, und einige vulgärere".

${ }^{14} \mathrm{El}$ artículo bestiame fue suprimido en DRAE 2001 (\$ 3.2).

${ }^{15}$ En el Tesoro de la lengua castellana o española (1611) de Covarrubias encontramos los siguientes textos: "VELO, el que lleua la nouia quando se casa, de donde se llamó aquel acto velambres, y ella y él, velado y velada", "Cerrarse las velambres, entrar los días en los quales no se celebran bodas por la Yglesia" (s. v. cerrar), "PADRINo, el que haze oficio de padre en el bautismo o confirmación, y en los velambres, y Missas nueuas". Tal y como se observa en la obra del canónigo de Cuenca, parece ser que normalmente el sustantivo se empleaba en plural, de ahí que muchos diccionarios recojan el lema en plural, como sucede en Autoridades (t. VI, 1739: "VELAMBRES. Véase Velaciones"). Además del texto alfonsí, pueden citarse otros (nótese en el segundo el uso de la unidad pluriverbal cerrar las velambres, recogida por Covarrubias): "En quanto a las obvenciones de entierros y honras, como en las de los baptizos, velambres, processiones y las demás semejantes, quedó acordado se ajusten los Clérigos con las lusticias y Regimientos de sus Pueblos dentro de vn mes" (Recopilación de las constituciones synodales del obispado de Sigüença con algunos motus proprios de los summos Pontífices, Alcalá de Henares, 1571, pp. 163-164; GB); "Desde Dominica de Aduiento hasta el día de los Reyes, inclusiue, se cierran las velambres, quiere dezir que la Dominica de Aduiento están cerradas, y el día de los Reyes también, dize desde el día de los Reyes hasta el día de la Ceniza exclusiue se abren las velaciones" (Pedro Ruyz Alcoholado, Tractado muy útil y curioso para saber bien rezar el officio Romano..., 1584, p. 41; GB). Huelga poner de relieve el parentesco etimológico que mantiene velación (< VELATIO, -ōNIS 'acción de tomar el velo') con velambre y velamen 'cubrimiento'.

${ }^{16}$ Con dos textos, uno de Antonio de Solís y Rivadeneyra (Historia de la conquista de México, 1684: "Sacando a tierra el velamen, xarcias y tablazón que podía ser de servicio") y otro de Pedro Calderón de la Barca (Ni amor se libra de amor, 1662: "Y desplegando el velamen, / que entre gúmenas y cuerdas / las ráfagas amainaron / de la passada tormenta").

${ }^{17}$ No merece la pena detenerse mucho en el término velaje. Acaso influido por la presencia de dicho sustantivo en la lexicografía académica, el Diccionario marítimo español (1831) señala en el artículo velamen: "El conjunto de las velas de un buque [...]. Antiguamente se decía velage". Autoridades recoge velage con la definición "El conjunto de velas de los navíos y armadas", pero no aportaba texto alguno. Se trata de una voz de rarísimo empleo en el español áureo, apenas documentada ("El mar empeçó a moverse, / passó después a alterarse; / nuestras Naos se dividieron / y yo siguiendo el parage / que los vientos me conceden, / sin arbitrio, sin examen; / los árboles destrozados, / hecho pieças el velage, / despedaçado el timón"; Francisco de Leiva Ramírez de Arellano, Amadís y Niquea, en Parte quarenta de comedias nuevas, Madrid, 1675, fol. 102r. ; GB).

${ }^{18}$ Basándose seguramente en $D C E C H$, el Gran diccionario de la lengua española (2012) de Larousse también propone la misma etimología catalana: "velamen (Del cat. velam.) Conjunto de velas de una embarcación)". Véase la nota 46.

${ }^{19}$ Como primera documentación Machado ofrece un texto de la Historia do descobrimento e conquista da India pelos portugueses (1551) de Fernão Lopes de Castanheda: "segudo enxergaua na grandeza dos velames pareciã naos grossas". ${ }^{20}$ También conocen esta voz el portugués y el catalán, pero en ambas lenguas su incorporación es tardía, además de que su presencia en ellas es insignificante (cfr. para el port. Frisoni 1917, DaviesP; y para el cat. DCVB, CICA y CTILC). Al igual que sucede en español con la voz ganado, los sustantivos guanyat (cat.) y gado (port.) hicieron innecesaria la presencia del italianismo en tales lenguas. El catalán, además, cuenta desde el s. XIII con el sustantivo colectivo bestiar "Conjunt 
d'animals quadrúpedes que s'aprofiten per al treball o per al consum; cast. ganado" (DCVB, s. v.; cfr. Diccionari Aguiló, Diccionari Balari, Faraudo).

${ }^{21}$ Por otro lado, en la parte español-italiano se ofrecen los siguientes equivalentes para ganado: "Armento, bestiame, gregge, greggia".

${ }_{22}^{2}$ Los corpus, las hemerotecas y otras fuentes consultadas no arrojan resultados significativos a partir del siglo XVII. CORDE ( 11 casos en 6 docs. de los Ss. XVI y XVII). Cfr. CNDH, CREA, CHARTA, CODEA, CORDIAM, CORPES, CV, etC.; HDBN, BVPH, BDMM, etc.

${ }^{23}$ Cfr. CORDE, CREA, CNDH, DaviesE, CHARTA, CORLEXIN, Fich. Ac., GB, etc.

${ }^{24}$ En la obra de Giovanni Sagrédo Memorie istoriche de’ monarchi ottomani (Bolonia, 1674) se utilizaba la voz legnami: "portando sacchi di lana, legnami" (p. 349).

${ }^{25}$ En Fich. Ac. hay una cédula sacada del Marco Bruto de Quevedo en la que se indica que el texto citado se corresponde con la " 2. a acepción", en alusión a "Provisión de leña", acepción que aparece en segundo lugar desde que se registró en 1803. ¿Pero realmente es un texto en que la voz leñame tiene tal valor? El texto dice así: "Y más nos han dicho, que las dichas dos naves habían cargado de leñame para vender en este puerto" (ed. L. Astrana Marín, Madrid, 1932, t. I, p. 630; Fich. Ac.). Aunque no se recoge en la mencionada cédula, en el texto de Quevedo, seguidamente, se emplea de nuevo la voz que nos interesa: "y que estando en la Costa de Marsella las hizieron descargar el dicho leñame". Si se lee atentamente el texto de Quevedo no puede afirmarse que se trate de la acepción indicada; leñame puede ser perfectamente 'madera para construir', y no para quemar. Según se nos alcanza, no estamos, por tanto, ante un testimonio de esa " $2 .{ }^{\text {a }}$ acepción".

${ }^{26}$ También en Autoridades con el lema emmaderamiento: "La obra hecha de madera, o cubierta de ella, como los techos y artesonados antiguos". A partir de DRAE 1780, enmaderamiento.

${ }^{27}$ A pesar de figurar contignación en los diccionarios de la Academia desde Autoridades, se trata de un latinismo de rarísimo uso en español.

${ }^{28}$ Véase la información que de maderamiento ofrecen CORDE, Fich. Ac., HDBN, BVPH, etc. Existen otras voces que derivan de madera con sentidos semejantes, pero que tienen poco interés para nosotros. Maderaje es otra de las palabras que entró en liza con maderamen; comenzó a utilizarse tímidamente a mediados del xVI y, aunque se documenta en las centurias siguientes, su empleo es poco significativo. Enmaderado 'conjunto de maderas' (no como participio de enmaderar) tiene escaso uso en español, pese a que también se documenta desde el XVI (cfr. CORDE y Fich. Ac.). Igualmente, maderación se documenta en el XVI, pero apenas ha dejado huella en español (cfr. CORDE). La vOz maderambre tiene menor interés aún, pues su uso es extremadamente raro; se documenta, por ejemplo, en el Vocabulario de la lengua bisaya (Manila, 1711; GB), de P. Mateo Sánchez: "Pusgo [... ]. Casa que hacen las hormigas, que llaman anay, en árboles, o en las cauezas de los harigues de las casas, o en otros encuentros de la maderambre, con que pudren y destruyen la cassa".

${ }^{29}$ Cunha (2019: s. v. madeira), sin embargo, indica que es voz del siglo Xx. Cfr. madeirame en DaviesP.

${ }^{30}$ Machado no incluye en el Dicionário etimológico da língua portuguesa (2003) ni madeirame ni madeiramento.

${ }^{31}$ Rainer (1993: 403) ejemplifica el uso del sufijo -ame en español únicamente con la voz poleame: "Das Suffix -ame hat kollektive Funktion: poleame (selten)".

${ }^{32}$ Dejamos al margen su registro lexicográfico, que no refleja en absoluto el uso real de este nombre. Poleame se incluyó en DRAE (1803: "El conjunto o acopio de poleas para una o más embarcaciones") y llega a DRAE (2014), donde se ha añadido la marca Mar[ina], pero ninguna cronológica.

${ }^{33}$ En italiano no existe *puleggiame, sino puleggie, plural de puleggia (cfr. GDLI). En catalán tampoco se formó *politjam y se utilizaron los plurales poliges, politges y politjas (cfr. Diccionari Aguiló, t. vI, 1929, s. v. polija; DCVB y Faraudo, s. v. politja).

${ }^{34}$ CIPM no ofrece documentación de poleame.

${ }^{35}$ Ello, desde luego, no invalida la procedencia portuguesa de la voz poleame. Al respecto, afirmaba Colón Doménech (1967: 219): "Cierto es que no hemos de ser esclavos de las fechas de aparición y no será raro el caso de que tegamos atestiguada antes una palabra en la lengua receptora que en la originaria". Es probable que no localizar el sustantivo poleame en textos portugueses más antiguos se deba, simplemente, a que los recursos con los que contamos para el estudio histórico del léxico portugués son notablemente menores que los disponibles para el estudio del español.

${ }^{36} \mathrm{El}$ texto de Mendes Pinto es la primera documentación que aduce Machado en su Dicionário etimológico da língua portuguesa (2003: s. v. poleame): "De polé. Séc. xVI [...]”. La traducción española de las Peregrinaciones (Madrid, 1620), 
llevada a cabo por el "Licenciado Francisco de Herrera Maldonado de la Santa Yglesia Real de Arbas", lee así: "Vergas, paueses, entenas, escudos, triças, áncoras y polijames" (p. 102b; GB). Herrera, que no debía de conocer las variantes españolas poleame y poleamen, creó el inusitado híbrido polijames a partir del nombre catalán polija y sobre el modelo portugués poleame, al que añadió el morfema de plural -s.

${ }^{37}$ Diogo de Couto empleó la voz poleame al menos en dos ocasiones más: [1596-1597] "muitas outras ousas da nao, amarras, ancoras, cordoalhas, mastos, vergas, entenas, cabrestantes, poleame, \& todas a mais cousas" (Década quinta da Asia, Lisboa, 1612, fol. 176r. $\left.{ }^{\circ} ; \mathrm{CB}\right) ;$ [1601-1603] "començaraõ a por em terra toda a cordoalha, maçame, poleame, entenas, vergas, leme” (Década sétima da Asia, Lisboa, 1616, fol. 39r.; GB).

38 "La vista del port ab son bosch de mástils y cordám, per entre 'Is cuals apenas s' ovirava l' interminable dellugadissa de la Riba" (Narcís Oller y Moragas, Cróquis del natural, s. l., Imprenta de la Renaixensa, 1879, p. 110; GB).

39 DICTER 2 (s. v. cordamen) también se decanta por la etimología italiana, si bien no manifiesta los motivos de tal vinculación.

${ }^{40}$ Diego Ufano (mediados del s. XVI?-c1613) fue un ingeniero militar español que sirvió en el ejército, desde finales del siglo XVI, bajo las órdenes de Luis de Velasco, general de la Artillería de Flandes. Su reconocimiento se debe principalmente al Tratado de artillería, donde se da cuenta de sus amplios conocimientos teóricos en tal materia, procedentes tanto de su experiencia militar como de la lectura de otros tratadistas. Por su parte, Alonso de Zepeda y Adrada (primera mitad de s. XVII?-segunda mitad del XVII) fue militar, astrónomo y matemático que vivió tanto en España como en los Países Bajos; a partir de 1660 se encuentra en Bruselas, donde ostentó varios cargos militares y trabajó al servicio de los gobernadores para la mejor fortificación de las plazas fuertes de Flandes. Finalmente, Sebastián Fernández de Medrano (1646-1705) llegó a ser uno de los más notables ingenieros militares españoles. Desde joven se inició en la lectura de tratados de arte militar. En 1667 se enroló en un tercio, en la compañía de Juan de Meneses, y fue destinado a Flandes como alférez. Tras la Guerra de la Devolución (1667-1668), continuó el estudio de los tratados militares y de las matemáticas y se especializó en fortificación y artillería. Pocos años después, en 1675, se fundó en Bruselas una academia donde enseñar matemáticas e ingeniería militar a soldados y oficiales españoles, y Fernández de Medrano empezó a dirigir dicha institución e impartir clases en ella. A partir de entonces comenzarían a ver la luz diversas publicaciones centradas en el arte militar.

${ }^{41}$ La documentación de la primera acepción registrada en GDLI ("Quantità, assortimento di corde; varietà di corde") parte de principios del siglo XIX: Targioni Tozzeti, D'Annunzio, etc. (Cfr. VAC5, con registro de cordame a partir de la 5. ${ }^{\text {a }}$ ed., 18631923, donde se recoge, en primer lugar, el citado texto de Corsini y, seguidamente, dos de Della palma de Magalloti; TLIO, sin información sobre cordame).

${ }^{42}$ Luis Collado, técnico militar sevillano destinado a Italia, donde llegó a ser ingeniero del Real Ejército de Lombardía y Piamonte, publicó en 1592 la misma obra en español, bajo el título Plática manual de artillería... (Milán); en ella se emplea en varias ocasiones la palabra "cuerdas" y una vez la voz cordería (vid. n. 44), pero no cordame(n).

${ }^{43}$ Es traducción de la obra de Pierre Boaistuau Le Théâtre du Monde (1558).

${ }^{44}$ Aunque es posible documentar cordelería desde finales del siglo XVI ("Cabestreros y cañameros, para que hagan sogas, maromas, gúmenas, cestas y espuertas y todo género de cordelería", Diego de Álava y Viamont, El perfeto capitán, instruido en la diciplina Militar y nueua ciencia de la Artillería, Madrid, 1590, fol. 75r. ${ }^{\circ}$; GB), esta voz comenzó a tener un uso considerable a partir de mediados del XVIII, lo que explica su inclusión en DRAE (1780; en realidad, se recogió en el manuscrito inédito de la C de Autoridades): "Lo mismo que CORDAGE, o CORDERía; y también el sitio donde se hace y la tienda donde venden todos géneros de cuerdas de cáñamo". A partir de entonces es fácil encontrar bastantes textos en los que tal sustantivo no solo tiene el sentido que nos interesa ('conjunto de cuerdas'), sino el de 'lugar donde se hace, y se venden, cuerdas' (cfr. Archive, BVPH, CORDE, Fich. Ac., GB, etc.). Igualmente, cordería ("El agregado de cuerdas", DRAE 1780) es un nombre que se documenta a finales del siglo XVII ("y de muchas Palas, Lanças, Açadas, Picos, Hachas, Sierras, Machos de hierro, Barras de hierro, Clauazón, Cordería y otras municiones para labrar en tierra", "Cordería de todas maneras", "Dos Romanas para pesar la póluora, y cordería, y sebo [...] Sessenta quintales de Cordería de Cáñamo de todas suertes", Bernardino de Escalante, Diálogos del arte militar, Sevilla, 1583, fols. 125v. ${ }^{\circ}$ 126v. ${ }^{\circ}$ y $129 r .{ }^{\circ}$; BVPH; "toda la cordería menuda" y "cordería gruessa y delgada” (Plática manual de artillería..., Milán, 1592, fols. 11r..$^{\circ}$ y 111v. ${ }^{\circ} ; \mathrm{GB}$ ); sin embargo, su uso es muy limitado durante las centurias posteriores (cfr. Archive, CORDE, GB, HDBN, etc.). Por otro lado, para la voz soguería el Fich. Ac. ofrece dos cédulas con varios testimonios del siglo xv, ambos vinculados con Aragón (CORDE ofrece un solo documento, de unas ordenanzas de Ávila: "[tiendas] de sogueria", 1485). El diccionario de la Academia registró en 1803, como provincial de Aragón, la acepción “El conjunto de sogas” y, medio siglo más tarde, 
Gerónimo Borao incluyó la misma voz, tomándola del DRAE, en su Diccionario de voces aragonesas (1859). No obstante lo anterior, y una vez consultadas distintas fuentes de información, se constata que el uso de soguería es muy escaso en español. Finalmente, el término cabuyería ("Conjunto cualquiera de cabos, y por consiguiente el total de los de un bajel. Alguna vez suele usarse por esta de la voz cabulla, y antiguamente se decía cordage”, Diccionario marítimo español, 1831, s. v. cabullería, variante gráfica empleada en algunas ocasiones) tiene algún uso a partir del siglo xIx: "algunos daños en el costado, velamen y cabullería" (Comercio Mercantil de España y sus Indias, 6 de abril de 1801, p. 220; HDBN; cfr. cabullería y cabuyería en Fich. Ac.).

${ }^{45}$ Aunque queda fuera de los límites cronológicos de este estudio, conviene indicar que el diccionario usual de 1884 registró un nuevo uso de botamen, que en un primer momento recibió la consideración de homónimo y, por tanto, se incluyó en un artículo aparte: "Conjunto de botes de una oficina de farmacia". Unos años más tarde (DRAE 1914) se recogieron bajo un mismo artículo las dos acepciones. El nuevo valor de botamen está bien documentado en español a partir de la primera mitad del siglo XVIII ("Se vende una botica con el botamen a la moderna y todos los enseres correspondientes"; Diario de avisos de Madrid, 29 de agosto de 1830, p. 971; HDBN) y llega a nuestros días (cfr. HDBN, BVPH, DEA).

${ }^{46}$ Como sucede con la etimología de velamen, el Gran diccionario de la lengua española (2012) de Larousse parece basarse en DCECH al proponer la misma etimología catalana: "botamen (Del cat. botam, conjunto de toneles)".

${ }^{47}$ Faraudo incluye en su Vocabulari de la llengua catalana medieval el siguiente texto de la Crònica del rey Pedro IV el Ceremonioso (s. XIV): "[... ] la nostra gent roba e barreja aquest barri; e tragueren ne molt vi que y havia e molt botam" (cfr. Diccionari Aguiló, t. I, y Diccionari Balari).

${ }^{48}$ Se define bottame en TLIO como "Contenitore composto da listelle di legno affiancate". Véase también la información que ofrecen VAC (s. v. bottume), Tomaseo y Bellini (1865-1879: s. v. bottame), GDLI (s. v. bottame y bottume) y DELI (s. v. botte: "bottame, s. m. 'insieme delle botti, dei tini e dei fusti di una cantina' (1350 ca., Crescenzi volgar)").

${ }^{49}$ Corominas toma el texto de DHist. (cfr. 72 ).

${ }^{50} \mathrm{CICA}$, en cambio, no aporta ningún documento.

${ }^{51}$ Barrilame se incluye en DRAE (1817): "Lo mismo que BARRILERÍA". Por otro lado, a la luz del texto de Horozco, la Academia, a partir de DHist./DRAE 1936-1939, registra la variante barrilamen.

${ }^{52}$ El Diccionario marítimo español (1831), que no recoge barrilamen, en el artículo botamen remite a pipería: "s. f. Nav. El conjunto de pipas o botas y aun cuarterolas y barriles en que se lleva la aguada y otros géneros. Llámase también vasigería y algunos dicen botamen. = It. Botame".

${ }^{53}$ Aunque barrilaje se documenta ocasionalmente en Jerónimo de Barrionuevo (Avisos, 1654-1664: "y que sus navíos carecen de barrilaje para hacer aguada", ed. Madrid, 1892, p. 428; Fich. Ac.), su uso se desarrolla en el español de México a partir del siglo XIX. Por otra parte, las voces tonelería 'conjunto de toneles' y vasijería 'pipería' datan del XVIII.

${ }^{54}$ Son muy conocidas las obras de Antonio de Valbuena Fe de erratas del nuevo diccionario de la Real Academia por D. (Miguel de Escalada) (4 ts., Madrid, 1887-1896), donde se recogió el artículo que nos ocupa (t. I, 1887, pp. 115-122) y Ripios académicos por D. - (Venancio González) (Madrid, [1890]).

${ }^{55}$ Poco después Commelerán reunió en un libro este y otros artículos que perseguían un mismo propósito: El Diccionario de la lengua castellana por la Academia Española. Colección de artículos publicados en La Controversia y El Liberal, en contestación a los que en El Imparcial ha dado a luz Miguel de Escalada contra la duodécima edición del Diccionario de la Real Academia Española (Madrid, 1887; cfr. p. 132).

${ }^{56}$ DCVB ofrece el siguiente texto de 1521, tomado del Diccionari Aguiló (t. vI, 1929): "Tota la rebuda qui's farà de la carn morta o del sèu e del pelam". Sin embargo, otras fuentes no ofrecen más testimonios antiguos del cat. pelam (cfr. CICA, Faraudo). Tampoco se recoge en CTILC y DDLC.

${ }^{57}$ En la misma línea se expresa Dworkin (2016: 544): “El papel importante de Portugal en la vida marítima del siglo xv y de la época premoderna explica la presencia de lusismos náuticos: angra, balde, buzo, callao, carabela, grúa, pleamar, tanque y los verbos amainar y virar".

${ }^{58}$ Tampoco lo tratan Nogueira (1945 y 1948), Álvarez Martínez (1997), Báez Montero (2006) y Corbella y Fajardo (2017).

${ }^{59}$ Recuérdese, no obstante, que pelamen tendrá una segunda oportunidad a partir del siglo XIX.

${ }^{60}$ Estos porcentajes proceden de los siguientes datos: 58 formas en -ame en los textos citados (36, s. XVI; 22, s. XVII); 55 formas en -amen en los textos citados (9, s. XVI; 46, s. XVII).

${ }^{61}$ Para los sustantivos cerdamen y pelamen CORDE ofrece, desde luego, sendos textos del Estebanillo.

${ }^{62}$ En DRAE (2014) solo reciben una marca cronológica las dos acepciones de leñame ("poc. us."). 